\title{
Geoquímica y mineralogía de la mina La Pava, Muzo- Quípama: implicaciones en la exploración de esmeraldas en Colombia
}

\author{
Andrés Felipe González-Durán ${ }^{1 *} \mathbb{D}$; Javier García-Toloza ${ }^{1}{ }^{(\mathbb{C}}$; Germán Bonilla ${ }^{2}$;

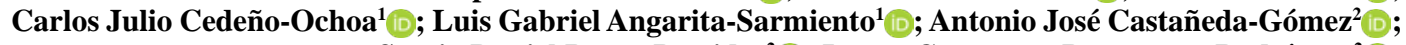 \\ Sergio Daniel Parra-Bastidas ${ }^{2}$ (D); Laura Constanza Bocanegra-Rodríguez ${ }^{2}$; \\ Jorge Montaña-Cárdenas ${ }^{2} \mathbb{D}$; Cesar Leonardo López-Castillo ${ }^{2}$
}

Forma de citar: González-Durán, A.F.; García-Toloza, J.; Bonilla, G.; Cedeño-Ochoa, C.J.; Angarita-Sarmiento, L.G.; Castañeda-Gómez, A.J.; Parra-Bastidas, S.D.; Bocanegra-Rodríguez, L.C.; Montaña-Cárdenas, J.; LópezCastillo, C.L. (2021). Geoquímica y mineralogía de la mina La Pava, Muzo-Quípama: implicaciones en la exploración de esmeraldas en Colombia. Boletín de Geología, 43(2), 117-142. https://doi.org/10.18273/revbol. v43n2-2021007

\section{Resumen}

La mina La Pava es parte del distrito esmeraldífero de Muzo-Quípama, Colombia; allí la presencia de esmeraldas se asocia con pelitas de la Formación Muzo. La mineralización es controlada espacialmente por el Anticlinal de La Pava — un pliegue por propagación de falla — y se restringe a zonas que han experimentado intensa alteración hidrotermal (albitización y carbonatización). Los principales rasgos observados en las venas productivas son las asociaciones paragenéticas de albita-xenotimo-fluorapatito y calcita-dolomita, los cuales van acompañados de anomalías geoquímicas positivas de Y, P, Mn y Mg. Adicionalmente, se presentan anomalías negativas de Li-Cs-Be-Ti que representan indicadores consistentes de la lixiviación de estos elementos en las rocas y su posterior concentración en venas y brechas hidrotermales. Se concluye que en La Pava existen parámetros estructurales, estratigráficos, mineralógicos y geoquímicos que permiten identificar bloques potenciales para hospedar mineralizaciones de esmeraldas.

Palabras clave: Esmeraldas; Exploración geoquímica; Formación Muzo; Colombia.

\section{Geochemistry and mineralogy of the La Pava mine, Muzo-Quípama: implications for emerald exploration in Colombia}

\begin{abstract}
The La Pava mine is located in the Muzo-Quípama district, Colombia; there, the emeralds are hosted by pelites from the Muzo Formation. The mineralization is spatially associated with the La Pava Anticline -a faultpropagation fold - and restricted to strongly altered zones (albitized and carbonatized). The main features displayed by the fertile veins are the mineral assemblages that include albite-xenotime-fluorapatite and calcitedolomite, and their corresponding positive geochemical anomalies: $\mathrm{Y}, \mathrm{P}, \mathrm{Mn}$, and Mg. Moreover, there is a consistent negative anomaly of Li-Cs-Be-Ti, which means these elements were effectively leached from the host rocks and subsequently concentrated as infill products in the hydrothermal veins. As a concluding remark, we identified a sort of parameters, regarding structures, stratigraphy, mineralogy, and geochemistry, that can be useful in defining exploration targets for emerald deposits.
\end{abstract}

Keywords: Emeralds; Geochemical exploration; Muzo formation; Colombia.

\footnotetext{
${ }^{1}$ Centro de Desarrollo Tecnológico de la Esmeralda Colombiana, Bogotá, Colombia. (*) geologist@gemlabcdtec.com, jagarciato@unal.edu.co,direccion@gemlabcdtec.com, ceo@gemlabcdtec.com

²Inclay, Bogotá, Colombia. gbonilla@inclaygeology.com, acastaneda@inclaygeology.com, sdparra@inclaygeology.com, l.bocanegra@inclaygeology.com, jmontana@inclaygeology.com, l.lopez@inclaygeology.com
} 


\section{Introducción}

Colombia sobresale en el mercado de las gemas por la alta calidad de sus esmeraldas; su finura se deriva del carácter particular de sus yacimientos, originados en un contexto geológico poco común. Los depósitos colombianos representan hasta el momento, la única fuente de esmeraldas encontradas en una cuenca sedimentaria afectada por hidrotermalismo no asociado a magmatismo (Cheilletz y Giuliani, 1996; Giuliani et al., 2019; Groat et al., 2008). Aunque existen reportes de otras localidades con ocurrencias en escenarios geológicos similares (Giuliani et al., 2019; Hewton et al., 2013), solo los depósitos de Colombia mantienen una importancia económica e histórica. Sin embargo, al observar las cifras de producción de las últimas décadas, existe una constante tendencia a la baja. En 2005 se produjeron $~ 6.746 .000$ quilates y en $2019 \sim 654.500$ quilates (UPME, 2020). Ante este panorama, se hace necesario intensificar la exploración de tal manera que nuevos descubrimientos puedan contribuir al aumento de la producción. Para ello es imprescindible disponer de un conocimiento geológico detallado de las minas actuales; partiendo del principio de que no se puede buscar lo que no se conoce. A pesar de que la comunidad científica ha contribuido con abundantes publicaciones sobre el origen y formación de los yacimientos esmeraldíferos, los estudios son generales y existen pocos reportes sobre los rasgos geológicos de una mina en particular. El objetivo de este trabajo es proveer información geoquímica, mineralógica y estructural sobre la mineralización de esmeraldas de la mina La Pava, Muzo-Quípama; para promover la definición de parámetros geológicos que conlleven a realizar una exploración satisfactoria.

\section{Contexto geológico}

Los depósitos esmeraldíferos en Colombia se distribuyen a lo largo de dos corredores en la Cordillera Oriental de los Andes (Moreno et al., 2009; Reyes et al., 2006; Terraza, 2019). La actual configuración tectónica de la Cordillera Oriental está ligada a diferentes procesos que han tenido lugar especialmente durante los últimos 150 Ma (Horton et al., 2020); se destaca la extensa acumulación de sedimentos principalmente marinos durante el Cretácico inferior, como parte del relleno de una cuenca de retro-arco (Teixell et al., 2015). En el Cretácico superior la dinámica extensional se vio interrumpida y la sedimentación empezó a ser controlada por el inicio del acortamiento cortical de la cuenca. Durante el Cenozoico, la compresión continuó y dio origen a secuencias predominantemente continentales. Finalmente, se dio paso a la exhumación y exposición de la actual cadena montañosa desde el Neógeno (Bayona, 2018; Horton et al., 2020; Kammer et al., 2020; Mora, 2007). Como resultado, la Cordillera Oriental está dominada por la presencia de sedimentitas, con exposiciones menores del basamento metamórfico y registros de actividad magmática muy restringidos (Bernet et al., 2016; Vásquez et al., 2010).

El distrito Muzo-Quípama es el principal productor de esmeraldas en la actualidad y se localiza a pocos kilómetros al NW del municipio de Muzo (Figura 1); hace parte del Cinturón Esmeraldífero Occidental junto con los distritos de Maripí, Coscuez, Peñas Blancas y Yacopí-La Palma (Reyes et al., 2006; Terraza, 2019). La mineralización de esmeraldas se asocia con pelitas y calizas del Valanginiano al Barremiano (Cheilletz y Giuliani, 1996; Giuliani et al., 1995; Mantilla et al., 2007; Reyes et al., 2006; Terraza, 2019). En la región de Muzo-Quípama la secuencia estratigráfica, en orden cronológico (de más antiguo a más joven), está compuesta por: la Formación Rosablanca que consta de una sucesión mayoritariamente calcárea de aproximadamente $1000 \mathrm{~m}$ de espesor; sobre ella descansan capas delgadas de lodolitas, limolitas y arcillolitas de la Formación Furatena, cuyo espesor oscila en $1000 \mathrm{~m}$. Posteriormente se encuentra la Formación Muzo, la cual corresponde a un paquete de 200-300 m de espesor conformado por lodolitas carbonosas, lodolitas calcáreas y niveles delgados y esporádicos de calizas. Finalmente, sobre la Formación Muzo se encuentran capas gruesas de limolitas y lodolitas silíceas de la Formación Capotes con 700 $\mathrm{m}$ de espesor (Reyes et al., 2006; Terraza, 2019). De acuerdo con diversos autores, en la zona de estudio la ocurrencia de esmeraldas se restringe exclusivamente a niveles de lodolitas calcáreas de la Formación Muzo (Mantilla et al., 2007; Moreno et al., 2009; Pignatelli et al., 2015; Reyes et al., 2006; Terraza, 2019). Desde el punto de vista tectónico, el distrito Muzo-Quípama se encuentra bajo la influencia de estructuras desarrolladas en un régimen transpresivo (Branquet et al., 1999; Laumonier et al., 1999; Reyes et al., 2006); la falla del Río Minero, la falla de Itoco y la falla de Peñas Blancas, son las estructuras mayores que configuran el área (Figura 1). El Anticlinal Alto La Chapa-Borbúr constituye un pliegue regional que ejerce influencia en la localización de zonas mineralizadas (Reyes et al., 2006). En La Pava se ha descrito una estructura de tipo flor positiva que permite la exposición de rocas de la Formación Muzo (Branquet et al., 1999); a escala más detallada, las labores mineras están ubicadas en 
Andrés Felipe González-Durán; Javier García-Toloza; Germán Bonilla; Carlos Julio Cedeño-Ochoa; Luis Gabriel Angarita-Sarmiento; Antonio José Castañeda-Gómez; Sergio Daniel Parra-Bastidas; Laura Constanza Bocanegra-Rodríguez; Jorge Montaña-Cárdenas; Cesar Leonardo López-Castillo

un dominio estructural caracterizado por pliegues apretados, particularmente el Anticlinal y Sinclinal de La Pava (Figura 2), los cuales se desarrollan en el bloque colgante de la falla El Águila, una estructura de cabalgamiento de alto ángulo con vergencia al occidente (González-Durán et al., 2019).

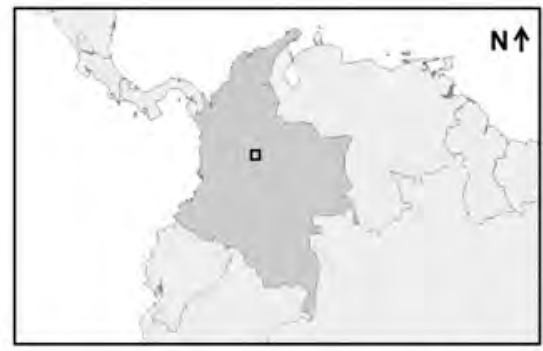

Unidades Litoestratigráficas

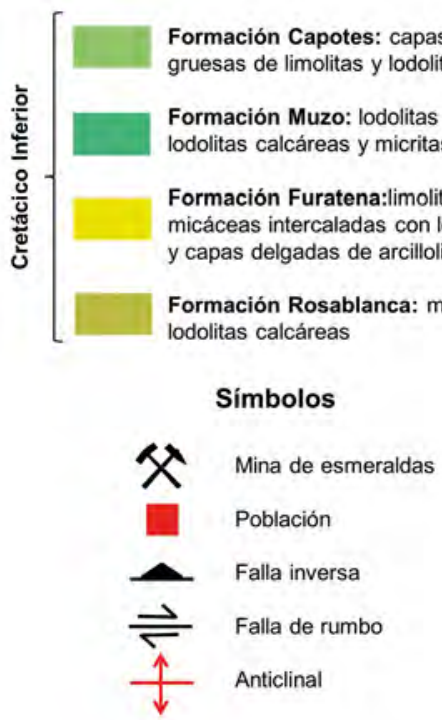

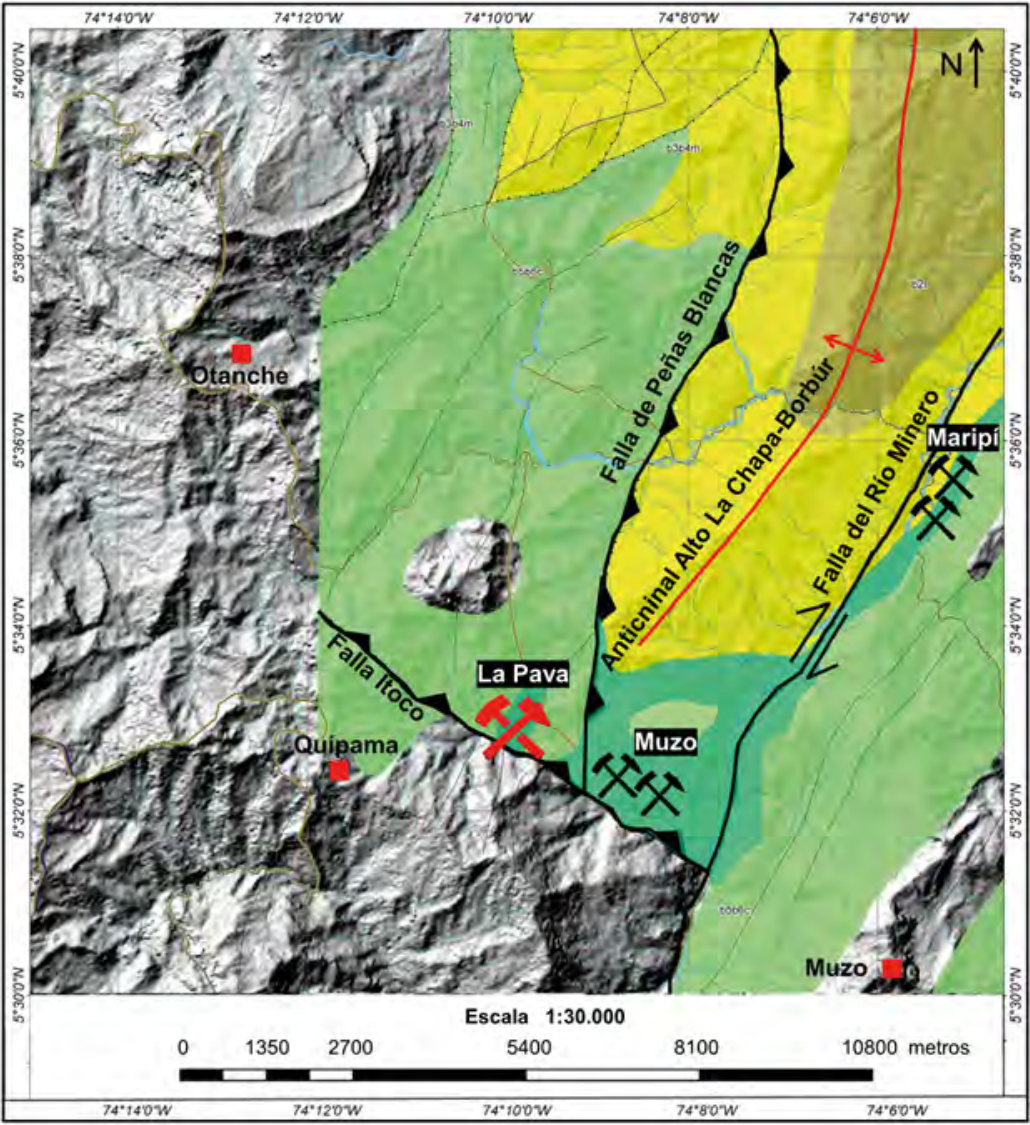

Figura 1. Mapa geológico generalizado que muestra la localización de los distritos mineros de Muzo-Quípama y Maripí. La ubicación de la mina La Pava se ha señalado en rojo. Modificado de González-Durán et al. (2019).

\section{Metodología}

Se realizó un levantamiento estratigráfico a escala 1:100, para lo cual se utilizó un bastón de Jacob con acople de rayo láser para medir los espesores de las capas. Se estudiaron dos secciones estratigráficas, una a lo largo del cauce del río Itoco y la otra sobre la quebrada La Pava. En ambas columnas se tomaron muestras de roca en intervalos de dos metros. Se seleccionaron 101 muestras de rocas, provenientes de las tres poblaciones — río Itoco, quebrada La Pava y túneles mineros- para determinar la composición química. Los análisis se realizaron en los laboratorios del Servicio Geológico Colombiano. Para la cuantificación de los óxidos de elementos mayores $-\mathrm{SiO}_{2}, \mathrm{Al}_{2} \mathrm{O}_{3}, \mathrm{TiO}_{2}, \mathrm{Fe}_{2} \mathrm{O}_{3}, \mathrm{MgO}, \mathrm{CaO}$ y $\mathrm{Na}_{2} \mathrm{O}$-, se emplearon muestras fundidas con una mezcla de meta y tetraborato de litio, mientras que para los elementos menores — Zr, Ge, Nb, Mo, Sn, Sb y Hfse utilizaron muestras prensadas. La cuantificación se llevó a cabo en un equipo de fluorescencia de rayos X, FRX Panalytical Axios Mineral. Los análisis de elementos trazas - Ni, Cu, As, Li, Cs, Be, V, Cr, Ba, Mn, Sc, Co, Zn, Ga, Rb, Sr, Cd, In, Y, Tl, Pb, Bi, Th y $\mathrm{U}$ - se realizaron en un espectrómetro de masas con plasma acoplado inductivamente, ICP-MS Perkin Elmer NEXION, luego de una digestión multiácida convencional (4 ácidos: $\mathrm{HF}, \mathrm{HNO}_{3}, \mathrm{HCl}$ y $\mathrm{HClO}_{4}$ ).

Adicionalmente, se realizaron análisis petrográficos de 35 secciones delgadas pulidas en un microscopio Olympus BX-51. Al tratarse de rocas pelíticas, se acudió a los diagramas de clasificación de Folk (1980) para rocas con componentes terrígenos. Así 
mismo, se seleccionaron 55 cristales de esmeraldas para análisis químicos mediante fluorescencia de rayos X. La cuantificación se realizó en un equipo de energía dispersiva PANalytical Epsilon 5. Ambos procedimientos se efectuaron en las instalaciones del Centro de Desarrollo Tecnológico de la Esmeralda Colombiana.

\section{Resultados}

\section{Mineralización}

La unidad predominante en el área es la Formación Muzo, presentándose como una secuencia dominada por limolitas negras monótonas. Se observan abundantes afloramientos a lo largo del cauce del río Itoco, la quebrada La Pava y el antiguo tajo de explotación a cielo abierto. La deformación tectónica es intensa, evidenciada por un fuerte clivaje —que generalmente enmascara la dirección de estratificación-, pliegues apretados y abundantes zonas de brechamiento. La mineralización de esmeraldas está asociada con zonas de brechas y venas con tendencia N10E, las cuales se disponen de manera paralela al plano axial del Anticlinal de La Pava; esto como resultado de un emplazamiento por deslizamiento flexural intracapas. La mayor concentración de venas productivas se distribuye en el núcleo del anticlinal y se proyecta hacia la charnela (Figura 2).

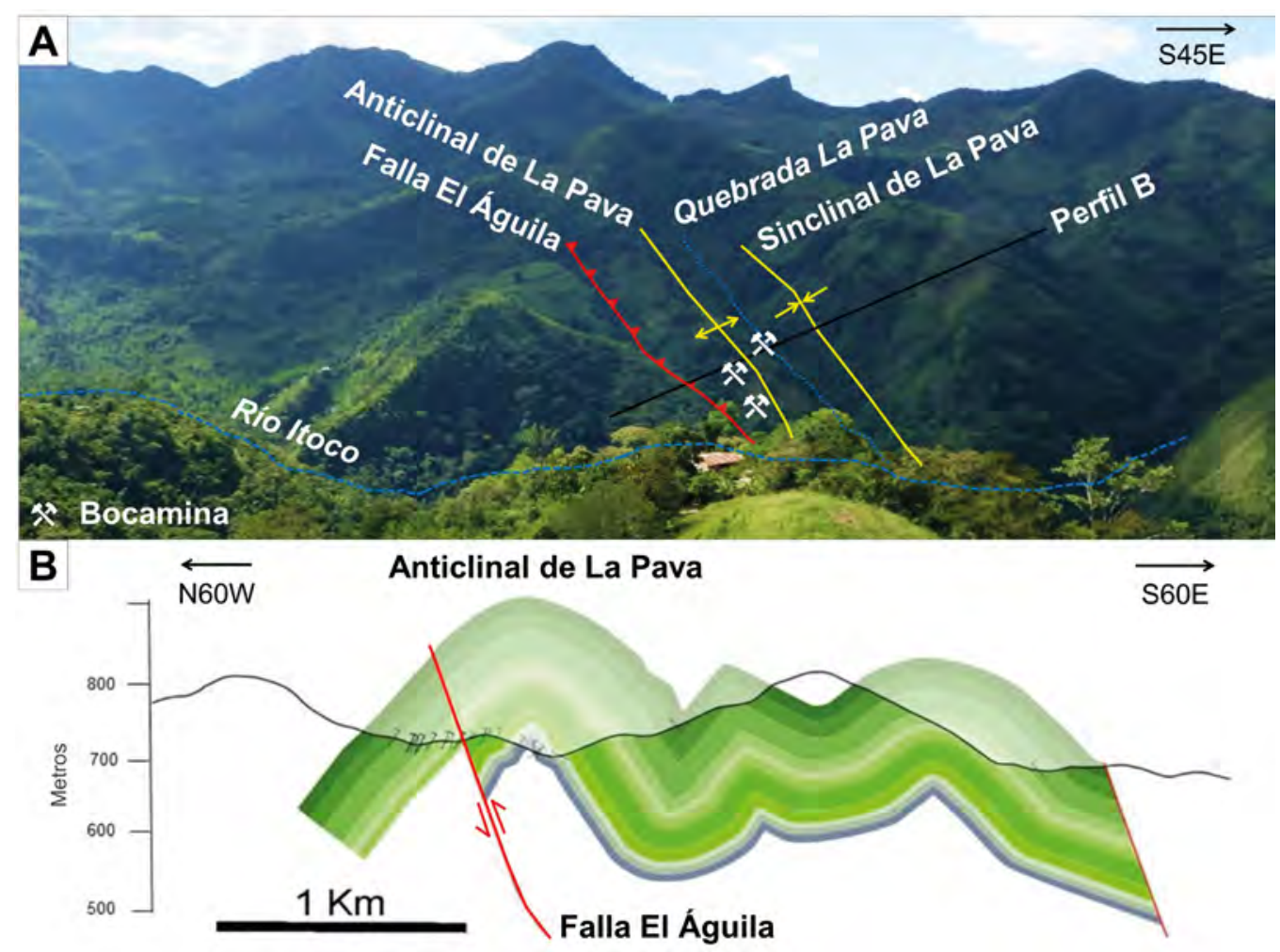

Figura 2. A. Vista panorámica de la zona de estudio con la localización del río Itoco, la quebrada La Pava —donde se realizaron los levantamientos estratigráficos - y el trazo de los principales rasgos estructurales. Nótese que la zona mineralizada se ubica en el núcleo del Anticlinal de La Pava. B. Perfil esquemático que muestra la configuración estructural del área. El Anticlinal de La Pava es interpretado como un pliegue por propagación de falla asociado a la falla El Águila. Modificado de González-Durán et al. (2019).

En el río Itoco aflora una capa de limolitas de color gris claro a beige, que exhiben una fuerte alteración hidrotermal (albitización y carbonatización) y que han sido afectadas por brechamiento tectónico; ese nivel se denomina "albititas" (Figura 3A). A escala de afloramiento estas rocas se presentan como un nivel de brechas estratiformes de seis metros de espesor; son de carácter polimíctico puesto que contienen clastos de rocas blancas albitizadas y limolitas negras levemente alteradas (Figura 3B); así mismo, algunos fragmentos de albititas presentan plegamientos tipo chevron (Figura 3C). El diámetro de los clastos varía entre 2 a $120 \mathrm{~cm}$, con textura caótica y matriz compuesta por material triturado. Las albititas tienen forma lenticular 
y su espesor puede disminuir hasta alcanzar unos pocos centímetros - como es el caso en la quebrada La Pava- Al interior de los túneles las albititas se encuentran altamente tectonizadas, son comunes los replegamientos, brechamientos y saltos por fallas locales (Figura 3D). Por el alto contraste de color que representan, las albititas son usadas como niveles guía por los mineros, debido a que las venas mineralizadas generalmente ocurren en zonas aledañas.

De manera local, se observan brechas hidrotermales con matriz de albita, cuyos cristales alcanzan los $2 \mathrm{~cm}$ de diámetro —exhiben textura "grano de arroz"-, y en menor proporción carbonatos, pirita y barita; estas brechas afectan las limolitas negras debajo de las capas de albititas. Aunque las brechas son locales, las zonas de albitización son de amplia extensión. Gran parte de las zonas albitizadas se encuentran sobreimpuestas por vetillas y venas de carbonatos — calcita y dolomitacon ocurrencia esporádica de esmeraldas (Figura 3E). Estas venas son a menudo drusiformes y el tamaño de los cristales es mayor a $1 \mathrm{~cm}$ de diámetro; las esmeraldas suelen ocurrir en espacios abiertos —en compañía de calcita, dolomita y albita - y típicamente se presentan como prismas hexagonales y di-hexagonales, en ocasiones con terminaciones de múltiples facetas con pirámides hexagonales y bi-hexagonales (Figura 4). Las esmeraldas de La Pava se caracterizan por su alta claridad y brillo, mientras que su color varía desde un verde levemente saturado a moderado, siendo el verde intenso muy poco común.

Las venas portadoras de esmeraldas no suelen superar los $25 \mathrm{~cm}$ de espesor, y con frecuencia se observan fenómenos de reapertura de antiguas venas de calcita fibrosa o albita. En algunos sectores hay ocurrencia de venas drusiformes de cuarzo y dolomita que pueden alcanzar los $120 \mathrm{~cm}$ de espesor. Ocasionalmente se encuentran sulfuros como pirita y calcopirita, aunque en bajas cantidades; también suelen encontrarse minerales tardíos que rellenan espacios tales como calcita — con habito "granizo" - y cristales euhedrales de barita dorada.

A nivel petrográfico las rocas hospedantes de la mineralización varían entre limolitas de grano medio a fino, arcillolitas y lodolitas con abundante contenido de materia orgánica. Se observan algunos niveles fosilíferos con presencia de foraminíferos planctónicos; también son comunes las intercalaciones entre niveles con distintos tamaños de grano y la afectación de estructuras sedimentarias por microdeformación (Figura 5A). A nivel composicional los principales constituyentes son las plagioclasas, micas y granos de cuarzo; como minerales traza se identificaron monacitas, zircones, rutilos, agregados de pirita framboidal y carbonatos.

Las rocas mineralizadas, especialmente las muestras colectadas en los túneles exhiben dos estilos de alteración hidrotermal muy definidos. El primer estilo corresponde a la albitización y se expresa mediante un intenso vetilleo y brechamiento hidrotermal, así como el reemplazamiento de los minerales formadores de roca (plagioclasas y micas) por albita. Las albitas se presentan comúnmente como cristales tabulares y maclados con crecimiento drusiforme (Figura 5B). Es claro distinguir múltiples generaciones de albita que se sobreimponen entre sí; en algunos sectores se observan vetillas que previamente contenían moscovita que han sido reabiertas por inyecciones de albita (Figura 5C). Si bien, la albita es el mineral predominante (más del 99\%), también suelen encontrarse esporádicamente cristales de xenotimo, pirita dodecaédrica, turmalina, rutilo y fluorapatito. Este último puede exhibir cristales de gran tamaño (1-3 cm de diámetro), de color rosado característico de las zonas esmeraldíferas. En las albititas, la albitización es intensa y consiste en un reemplazamiento casi total de la roca original. El reemplazamiento genera blanqueamiento, en el sentido que el color de la nueva roca es generalmente gris claro o beige, un hecho que contrasta con el color negro original de las limolitas (Figura 3).

El segundo estilo de alteración hidrotermal corresponde a la carbonatización. Este evento es posterior a la albitización y se caracteriza por la abundante ocurrencia de carbonatos: dolomita y calcita. Ambos minerales se encuentran como cristales romboédricos al interior de venas, conformando la matriz de brechas hidrotermales o como cristales diseminados en las rocas albitizadas (Figura 5D, 5E). Es común observar cristales de albita con bordes corroídos por el reemplazamiento parcial por carbonatos; también ocurren otras texturas indicativas de reemplazamiento como pseudomorfos e inclusiones relícticas. A diferencia de la albitización que consta de vetillas delgadas, los carbonatos suelen encontrarse en venas con espesores que oscilan entre los 2 y los $25 \mathrm{~cm}$. Las rocas circundantes a las venas generalmente reaccionan ante el ácido clorhídrico por el alto contenido de calcita. 

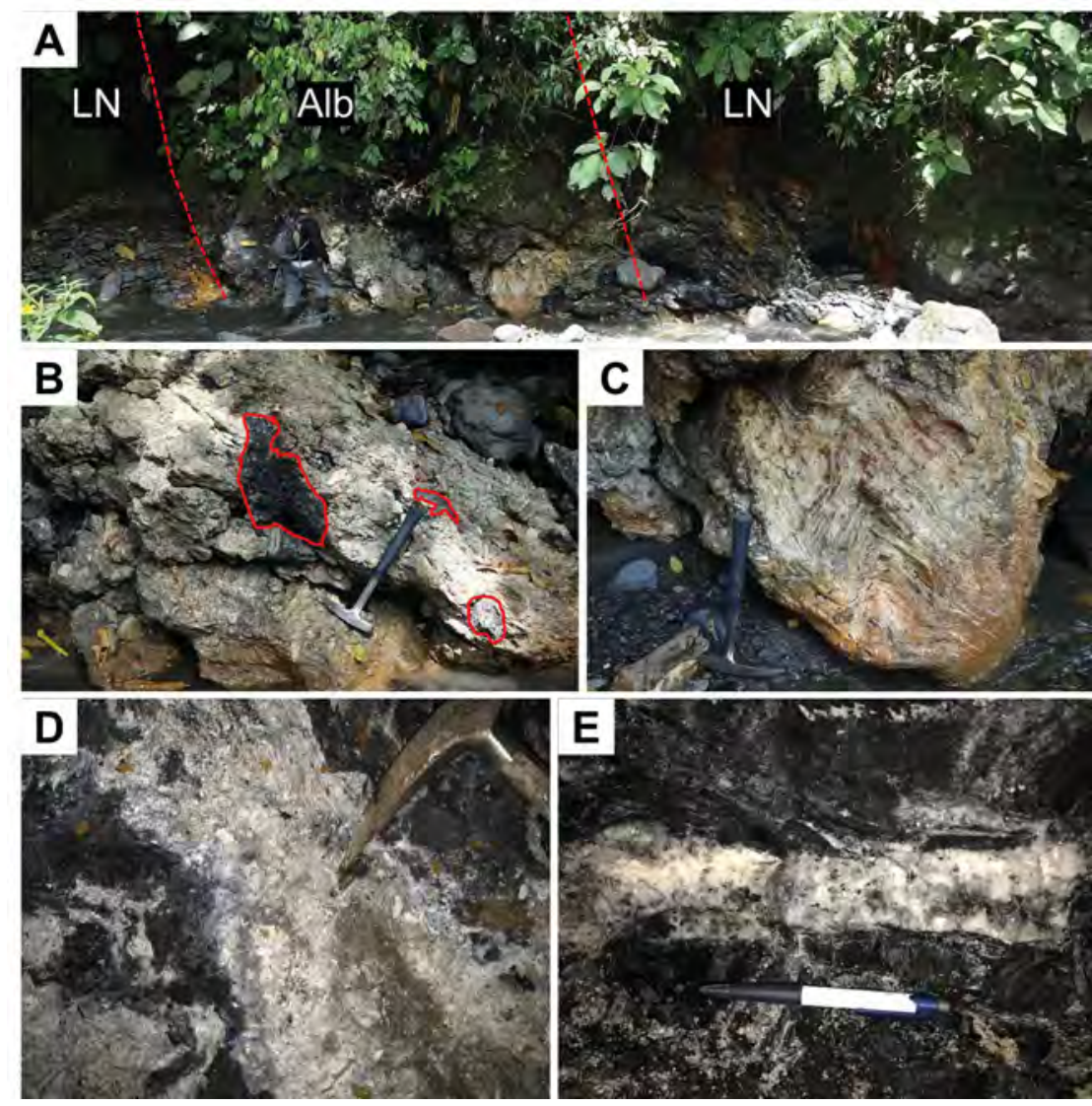

Figura 3. Fotografías de campo. A. Nivel de albititas estratiformes y brechadas aflorando en el río Itoco. Se trata de un nivel de aproximadamente seis metros de espesor, con rocas de color beige-gris claro, rodeado por limolitas negras. B. Brecha polimíctica con fragmentos de limolitas negras y albititas de color beige; río Itoco. C. Fragmento de albitita con pliegues tipo Chevron; río Itoco. D. Zona tectonizada con fragmentos de albititas y limolitas negras. Nótese el color amarillo dentro de las albititas, el cual se debe a la presencia de azufre nativo; vista al interior de los túneles. E. Vena de dolomita, albita y calcita hospedada por limolita negra albitizada y carbonatizada; vista al interior de los túneles. LN: limolita negra, Alb: albitita.

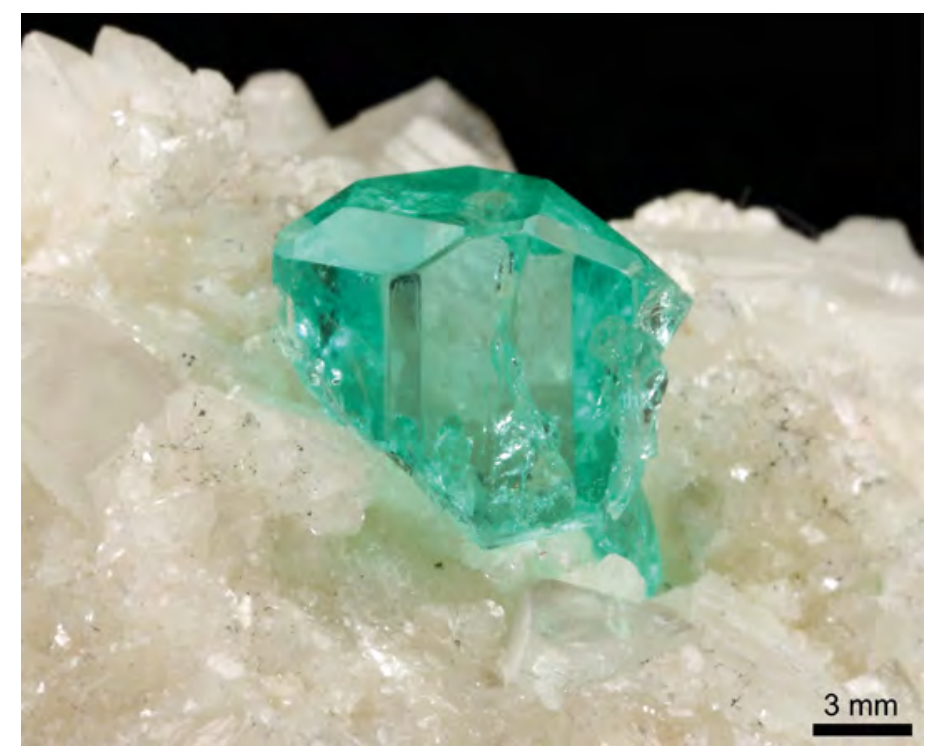

Figura 4. Vena de calcita blanca con esmeralda. Nótese la transparencia y el color levemente saturado de la esmeralda; además de su compleja configuración cristalográfica. Fotografía cortesía de Gérard Martayan. 
Otros minerales que también hacen parte de este ensamblaje, pero que ocurren en mucho menor proporción, son cuarzo, moscovita, albita, pirita dodecaédrica, calcopirita, esfalerita y esmeralda (Figura 5F, 5G). La ocurrencia de esmeraldas en vetillas compuestas únicamente por albita es casi nula. En las albititas, la carbonatización generalmente está acompañada por la ocurrencia de azufre nativo, junto con cristales de cuarzo, los cuales particularmente contienen abundantes inclusiones de fragmentos de rocas, cristales de moscovita y fragmentos de anhidrita que posiblemente sean relictos de la etapa de albitización.
Finalmente, se presenta una etapa hidrotermal tardía caracterizada por la ocurrencia de barita, siderita y yeso (Figura $5 \mathrm{H}$ ). Estos minerales se encuentran, en su mayoría, como relleno de espacios abiertos y por lo tanto exhiben formas euhedrales. Por otro lado, la oxidación supérgena ha dado origen a la ocurrencia de goethita, malaquita y covelina a partir de la alteración de pirita y calcopirita. Los carbonatos que contienen hierro (dolomita y siderita) también se ven afectados por la oxidación y suelen mostrar pátinas, reemplazamientos y textura boxwork con óxidos e hidróxidos de hierro. La Figura 6 muestra una secuencia paragenética esquemática y generalizada de la mineralización de La Pava.
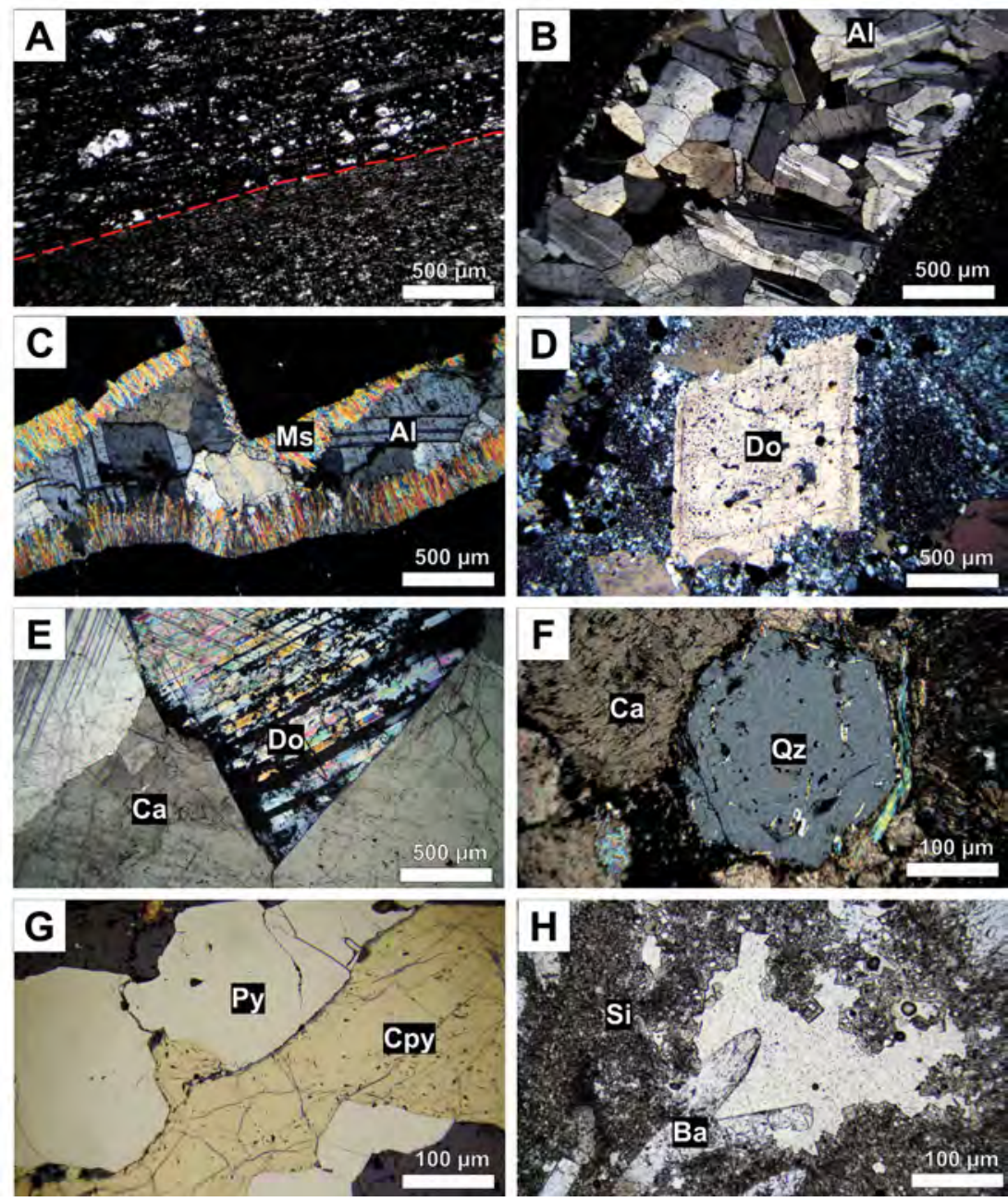

Figura 5. Microfotografías. A. Lodolita negra carbonosa del río Itoco. La línea roja corresponde a un contacto entre dos niveles con diferente tamaño de grano; PPL. B. Lodolita negra cortada por una vetilla de albita; XPL. C. Arcillolita carbonosa con una vetilla de moscovita y albita. La vetilla inicialmente contenía moscovita y fue reabierta recibiendo un relleno de albita; XPL. D. Cristales de dolomita romboédrica en roca fuertemente albitizada; XPL. E. Vetilla con dos carbonatos: calcita y dolomita; XPL. F. Cristal de cuarzo, rodeado por calcita, con forma hexagonal e inclusiones de moscovita. La muestra hace parte de la albitita del río Itoco; XPL. G. Vetilla con pirita y calcopirita. Nótese que la calcopirita contiene delgadas líneas azules que corresponden a covelina supergénica; PPR. H. Oquedad parcialmente rellena por cristales euhedrales de barita y siderita; PPL. PPL: luz polarizada plana; XPL: luz polarizada con nicoles cruzados; PPR: luz reflejada plana; Al: albita, Ba: barita; Ca: calcita, Cpy: calcopirita; Do: dolomita; Ms: moscovita; Py: pirita; Qz: cuarzo; Si: siderita. 


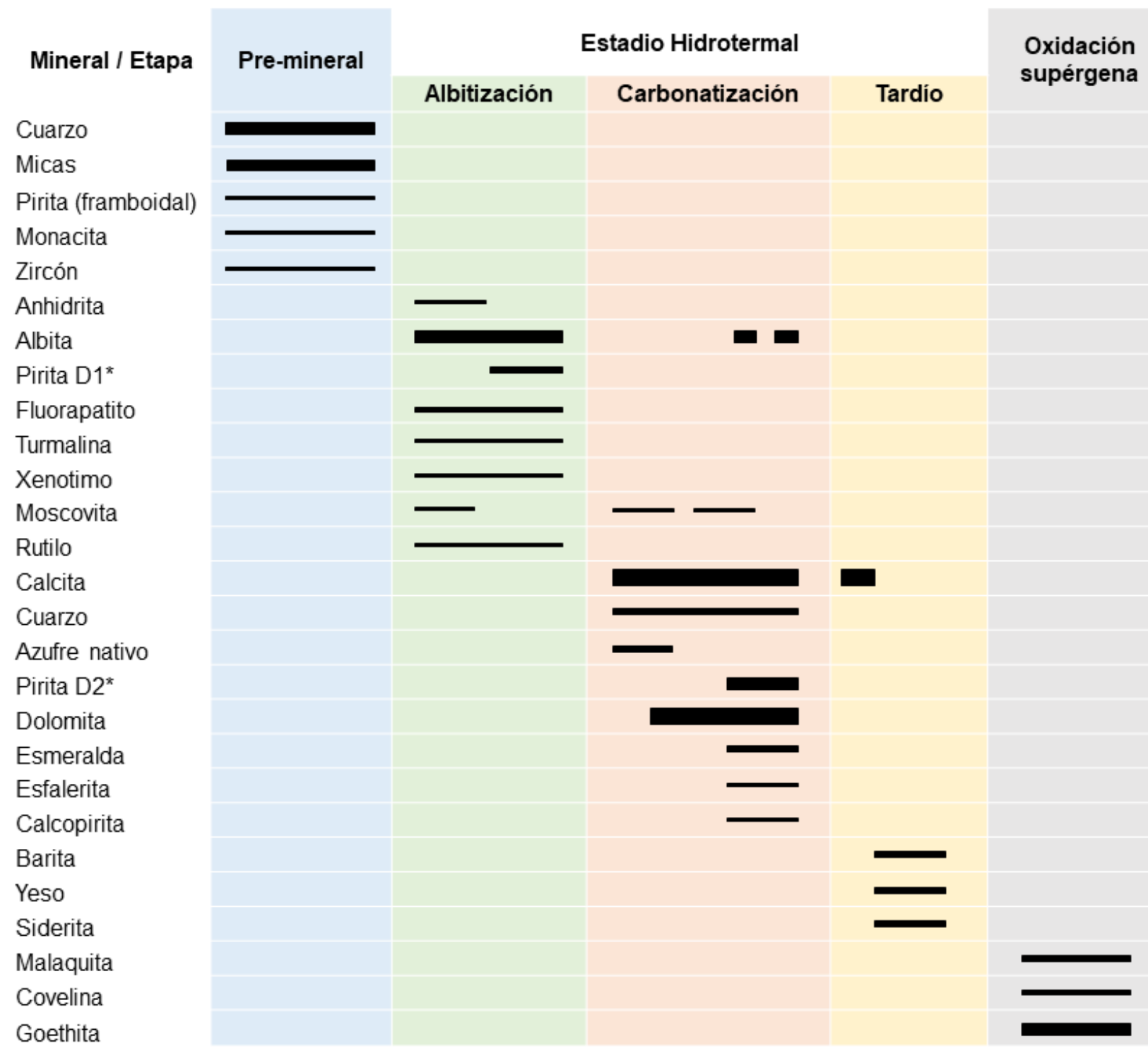

Figura 6. Secuencia paragenética generalizada de la mineralización en La Pava. *D: dodecaédrica.

\section{Geoquímica de rocas}

Para el análisis geoquímico de roca total, las muestras se dividieron en tres grupos con base en el criterio geológico de las observaciones en campo. El primer grupo abarca 68 muestras de limolitas negras recolectadas en la ribera del río Itoco, las cuales corresponden a una zona con poca manifestación de alteración hidrotermal (a excepción del nivel de albititas) y por lo tanto se asume que los resultados representan valores cercanos a la composición original de las rocas antes de la mineralización. El segundo grupo corresponde a 19 muestras de limolitas negras recolectadas en la quebrada La Pava; allí se observaron rasgos claros de alteración hidrotermal, entre ellos zonas de vetilleo y brechas hidrotermales. En tercer lugar, se encuentran 14 limolitas negras fuertemente alteradas hidrotermalmente, adquiridas al interior de los túneles en cercanías a venas portadoras de esmeraldas; por lo tanto, constituyen testigos de primera mano del metasomatismo responsable de formar las esmeraldas. Las Tablas 1 y 2 muestran un resumen estadístico de los resultados de los análisis geoquímicos para los tres grupos de muestras; los datos pueden ser consultados en los Anexos 1 y 2. 
En general, las muestras están dominadas por las concentraciones de $\mathrm{SiO}_{2}(40,6-57,1 \%)$ y $\mathrm{Al}_{2} \mathrm{O}_{3}(11,3-$ $22,6 \%$ ) con cantidades menores de otros elementos como $\mathrm{Fe}_{2} \mathrm{O}_{3}, \mathrm{Na}_{2} \mathrm{O}, \mathrm{K}_{2} \mathrm{O}, \mathrm{CaO}, \mathrm{TiO}_{2}$ y $\mathrm{MgO}$, mientras que la concentración promedio de $\mathrm{P}_{2} \mathrm{O}_{5}$ no sobrepasa el $1 \%$. La variación de la mayoría de los datos es alta en cada grupo de muestras, en especial en elementos de fácil movilidad como $\mathrm{Ca}$, $\mathrm{Fe}$ y $\mathrm{Mg}$ donde la desviación estándar supera en magnitud en algunos casos al valor medio. El promedio de pérdida de componentes por ignición (LOI) oscila entre 8,5\% y $18,8 \%$, lo cual sugiere un aporte considerable de componentes orgánicos y elementos volatilizables. En cuanto a elementos traza, la variación sigue siendo alta para la mayoría, principalmente en elementos litófilos como $\mathrm{Mn}$ y $\mathrm{V}$, y aún más acentuada en elementos calcófilos como Mo, $\mathrm{Zn}, \mathrm{Cd}, \mathrm{Ni}$, y As. La Figura 7 muestra dos columnas litoestratigráficas levantadas en el río Itoco y la quebrada La Pava; estas incluyen una representación gráfica de los porcentajes relativos de elementos mayores y registros de algunos elementos trazas (Be, $\mathrm{Cr} / \mathrm{V}$, Mn e Y). La sección del río Itoco abarca la parte superior de la Formación Muzo y la base de la Formación Capotes; el contacto se encuentra aproximadamente en el metro 150. El atributo más sobresaliente está relacionado con el nivel de albititas comprendido entre los 130-140 m. El principal rasgo que diferencia este nivel de toda la sección es el aumento en la concentración de $\mathrm{Ca}, \mathrm{Mg}$, Mn e Y. De manera recíproca, las concentraciones de Ti, K y Be disminuyen considerablemente. La relación $\mathrm{Cr} / \mathrm{V}$ se mantiene relativamente constante en la parte superior de la sección, mientras que en la periferia de las albititas y en la parte inferior exhibe fluctuaciones. En adición a los elementos expuestos en la gráfica, casi la totalidad de los elementos analizados muestran cambios notables en las albititas. Por otra parte, el Fe y el Ca presentan un aumento gradual hacía la parte alta de la sección, el cual contrasta con una disminución en el contenido de $\mathrm{Na}$.

En la sección de la quebrada La Pava, se observa una mayor abundancia en las concentraciones de $\mathrm{Ca}, \mathrm{Na}$ e Y en comparación con el río Itoco; de igual forma, las oscilaciones de la mayor parte de los elementos también son más recurrentes. En el intervalo comprendido entre 20-110 m (el bloque más afectado por la actividad hidrotermal), se observa un incremento sustancial en los valores de $\mathrm{Ca}$, localmente de $\mathrm{Mg}$, $\mathrm{y}$ una disminución drástica en el contenido de $\mathrm{Na}$; sin embargo, hacia la parte superior, la concentración de $\mathrm{Na}$ aumenta de tal manera que alcanza proporciones cercanas al $95 \%$, específicamente en el metro 100 . El Be exhibe empobrecimientos en varios sectores sin mostrar zonas de incrementos sustanciales (un comportamiento similar al del $\mathrm{Cr}$ y V), mientras que el $\mathrm{Y}$ tiende a mostrar incrementos con valores cercanos a los alcanzados en el nivel de albititas del río Itoco. El Mn muestra un enriquecimiento en el intervalo de 40-50 m, el cual se correlaciona de manera directa con el $\mathrm{Mg}$. La relación $\mathrm{Cr} / \mathrm{V}$ presenta fluctuaciones a lo largo de toda la sección. Los contenidos de Fe y Ti no presentan variaciones considerables ni se observa una tendencia.

La Figura 8 muestra una comparación gráfica entre la composición promedio de las rocas del río Itoco, normalizada con respecto a la composición de la corteza continental superior provista por Rudnick y Gao (2014). Gran parte de los elementos exhiben ligeras variaciones; sin embargo, las anomalías más notables corresponden al enriquecimiento de Mo — más de $\approx 50$ veces - junto con aumentos menores en los contenidos de As, Cd, V y Bi. Por otro lado, los empobrecimientos más notables corresponden a los valores de $\mathrm{Mg}, \mathrm{Mn}, \mathrm{Co}$, Sr, Y y Pb. Cabe resaltar que el Be, elemento indispensable para la formación de las esmeraldas, exhibe tan solo un ligero aumento - alrededor de 2 veces - con respecto al valor medio de la corteza.

En adición, se construyó un diagrama multielementos para visualizar gráficamente las principales anomalías geoquímicas. Se tomó como línea base o valor de fondo los valores promedio del río Itoco. El eje "y" representa la diferencia entre el promedio de los valores del río Itoco, La Pava y los túneles, sobre la desviación estándar del río Itoco (Figura 9). Las líneas grises punteadas representan dos desviaciones estándar, de modo que los valores que son mayores a 2 son vistos anomalías positivas y los valores menores a -2 como anomalías negativas (Gandhi y Sarkar, 2016). 
Tabla 1. Resumen estadístico de elementos mayores, menores y algunos traza de la mina La Pava.

\begin{tabular}{|c|c|c|c|c|c|c|c|c|c|c|c|c|c|c|c|c|c|c|}
\hline & $\mathrm{SiO}_{2}$ & $\mathrm{Al}_{2} \mathrm{O}_{3}$ & $\mathrm{TiO}_{2}$ & $\mathrm{Fe}_{2} \mathrm{O}_{3} \mathrm{~T}$ & MgO & $\mathrm{CaO}$ & $\mathrm{Na}_{2} \mathrm{O}$ & $\mathrm{K}_{2} \mathrm{O}$ & $\mathbf{P}_{2} \mathbf{O}_{5}$ & LOI & Total & $\mathrm{Zr}$ & Ge & $\mathrm{Nb}$ & Mo & Sn & Sb & Hf \\
\hline \multicolumn{19}{|c|}{ Río Itoco } \\
\hline $\mathrm{n}$ & 68 & 68 & 68 & 68 & 68 & 42 & 68 & 68 & 51 & 68 & 68 & 68 & 36 & 67 & 57 & 26 & 21 & 23 \\
\hline Min & 23,7 & 5,2 & 0,2 & 0,2 & 0,1 & 0,1 & 0,2 & 0,5 & 0,03 & 3,9 & 93,5 & 55 & 2 & 11 & 2 & 8 & 12 & 8 \\
\hline Max & 70,4 & 28,5 & 1,5 & 33,8 & 6,0 & 32,8 & 9,3 & 4 & 0,46 & 23,6 & 99,9 & 310 & 4 & 36 & 368 & 16 & 35 & 19 \\
\hline Prom & 57,1 & 22,6 & 1,1 & 4,0 & 0,5 & 1,8 & 2,3 & 2,1 & 0,14 & 8,5 & 99,5 & 168 & 3 & 24 & 46 & 9 & 19 & 10 \\
\hline Med & 58,6 & 23,7 & 1,1 & 2,4 & 0,3 & 0,2 & 2,0 & 2,2 & 0,12 & 8,0 & 99,7 & 158 & 3 & 25 & 20 & 9 & 15 & 9 \\
\hline De & 7,7 & 4,4 & 0,3 & 5,6 & 0,8 & 5,9 & 1,3 & 0,6 & 0,09 & 3,0 & 0,9 & 58 & 1 & 7 & 65 & 2 & 7 & 3 \\
\hline \multicolumn{19}{|c|}{ Quebrada La Pava } \\
\hline $\mathrm{n}$ & 19 & 19 & 19 & 19 & 18 & 18 & 19 & 16 & 17 & 19 & 19 & 19 & 10 & 19 & 19 & 2 & 17 & 4 \\
\hline Min & 9,7 & 2,9 & 0,1 & 0,2 & 0,1 & 0,1 & 0,1 & 0,1 & 0,03 & 2,6 & 96,8 & 25 & 2 & 5 & 3 & 8 & 14 & 8 \\
\hline Max & 70,5 & 24,2 & 1,1 & 13,7 & 14,4 & 27,2 & 10,6 & 4,9 & 0,58 & 38,4 & 99,9 & 178 & 5 & 25 & 815 & 10 & 31 & 11 \\
\hline Prom & 56,1 & 16,2 & 0,6 & 3,6 & 1,1 & 3,6 & 3,2 & 2,4 & 0,27 & 12,9 & 99,3 & 106 & 3 & 15 & 170 & 9 & 19 & 9 \\
\hline Med & 58,1 & 16,4 & 0,6 & 3,8 & 0,3 & 0,5 & 1,2 & 2,3 & 0,28 & 12,0 & 99,6 & 105 & 2 & 15 & 110 & 9 & 17 & 9 \\
\hline De & 13,0 & 5,2 & 0,3 & 2,9 & 3,3 & 7,2 & 3,4 & 1,2 & 0,20 & 7,0 & 0,8 & 37 & 1 & 5 & 206 & 1 & 5 & 1 \\
\hline \multicolumn{19}{|c|}{ Túneles } \\
\hline $\mathrm{n}$ & 14 & 14 & 14 & 14 & 14 & 14 & 14 & 14 & 14 & 14 & 14 & 14 & - & 14 & 14 & - & 4 & 10 \\
\hline Min & 21,9 & 5,3 & 0,1 & 1,2 & 0,3 & 2,9 & 0,4 & 0,3 & 0,07 & 7,8 & 96,2 & 32 & - & 5 & 2 & - & 12 & 8 \\
\hline Max & 59,6 & 18,3 & 1,0 & 8,6 & 9,2 & 28,3 & 7,4 & 4 & 0,62 & 28,8 & 98,7 & 168 & - & 19 & 179 & - & 22 & 125 \\
\hline Prom & 40,6 & 11,3 & 0,5 & 4,1 & 3,7 & 13,6 & 3,8 & 1,2 & 0,30 & 18,8 & 97,8 & 85 & - & 12,0 & 31 & - & 17 & 26 \\
\hline Med & 40,8 & 11,6 & 0,4 & 4,1 & 2,3 & 15,3 & 3,5 & 0,8 & 0,30 & 19,5 & 97,8 & 90 & - & 12 & 4 & - & 17 & 13 \\
\hline De & 11,1 & 3,9 & 0,3 & 1,9 & 3,2 & 8,3 & 2,3 & 1,1 & 0,16 & 6,5 & 0,8 & 40 & - & 5 & 58 & - & 4 & 35 \\
\hline Lc & 0,36 & 0,18 & 0,04 & 0,1 & 0,1 & 0,1 & 0,11 & 0,08 & 0,024 & 0,1 & - & 2 & 2 & 2 & 2 & 8 & 12 & 8 \\
\hline
\end{tabular}

Elementos mayores y menores reportados en \% en peso; elementos trazas reportados en ppm en peso (Zr, Ge, Nb, Mo, Sn, Sb y Hf). LOI: \% pérdida de peso por ignición; Fe $\mathrm{O}_{3} \mathrm{~T}$ hace referencia al hierro total $\left(\mathrm{Fe}^{2+}+\mathrm{Fe}^{3+}\right)$. n: número de muestras, Min: valor mínimo, Max: valor máximo, Prom: promedio, Med: mediana, De: desviación estándar y Lc: límite de cuantificación. 
Tabla 2. Resumen estadístico de elementos traza expresados en ppm en peso de la mina La Pava.

\begin{tabular}{|c|c|c|c|c|c|c|c|c|c|c|c|c|c|c|c|c|c|c|c|c|c|c|c|c|}
\hline & $\mathrm{Ni}$ & $\mathrm{Cu}$ & As & $\mathbf{L i}$ & Cs & Be & $\mathbf{V}$ & $\mathrm{Cr}$ & Ba & Mn & Sc & Co & Zn & Ga & $\mathbf{R b}$ & $\mathrm{Sr}$ & Cd & In & $\mathbf{Y}$ & Tl & $\mathbf{P b}$ & $\mathbf{B i}$ & Th & $\mathbf{U}$ \\
\hline \multicolumn{25}{|c|}{ Río Itoco } \\
\hline$n$ & 68 & 68 & 68 & 68 & 68 & 68 & 68 & 68 & 68 & 68 & 68 & 68 & 68 & 68 & 68 & 68 & 68 & 68 & 68 & 68 & 68 & 68 & 68 & 68 \\
\hline Min & 3 & 6 & 2 & 1 & 0,4 & 0,6 & 44 & 17 & 37 & 4 & 6,1 & 0,2 & 6 & 7,1 & 22 & 23 & 0,1 & 0,01 & 1,2 & 0,2 & 2 & 0,1 & 1,4 & 0,9 \\
\hline Max & 390 & 78 & 166 & 179 & 15,0 & 7,3 & 2051 & 290 & 714 & 1713 & 41,7 & 64 & 627 & 36,8 & 191 & 173 & 9,0 & 0,10 & 14,2 & 4,3 & 25 & 1,4 & 22,4 & 11,3 \\
\hline Prom & 32 & 18 & 10 & 55 & 8,1 & 3,5 & 409 & 111 & 357 & 144 & 16,4 & 7 & 46 & 27,7 & 122 & 108 & 0,6 & 0,05 & 3,6 & 1,4 & 7 & 0,5 & 12,6 & 2,2 \\
\hline Med & 22 & 13 & 7 & 56 & 8,2 & 3,4 & 227 & 100 & 365 & 43 & 16,0 & 2 & 19 & 29,1 & 121 & 117 & 0,4 & 0,04 & 2,8 & 1,4 & 6 & 0,5 & 13,3 & 1,7 \\
\hline De & 49 & 15 & 20 & 29 & 3,4 & 1,1 & 458 & 50 & 124 & 266 & 4,7 & 10 & 96 & 5,7 & 38 & 37 & 1,1 & 0,02 & 2,5 & 0,7 & 5 & 0,2 & 4,3 & 1,5 \\
\hline \multicolumn{25}{|c|}{ Quebrada La Pava } \\
\hline$n$ & 19 & 19 & 19 & 19 & 19 & 19 & 19 & 19 & 19 & 19 & 19 & 19 & 19 & 19 & 19 & 19 & 19 & 19 & 19 & 19 & 19 & 18 & 19 & 19 \\
\hline Min & 4 & 8 & 2 & 1 & 0,1 & 0,3 & 12 & 5 & 10 & 2 & 0,3 & 0,4 & 6 & 1,6 & 1 & 16 & 0,1 & 0,005 & 0,8 & 0,1 & 2 & 0,1 & 0,8 & 0,3 \\
\hline Max & 289 & 99 & 100 & 72 & 10,2 & 4,6 & 2122 & 216 & 587 & 689 & 24,2 & 12 & 273 & 35,4 & 211 & 290 & 9,6 & 0,13 & 20,4 & 6,5 & 66 & 0,9 & 34,1 & 21,2 \\
\hline Prom & 110 & 38 & 41 & 19 & 3,2 & 2,2 & 811 & 127 & 286 & 92 & 12,5 & 6 & 72 & 21,3 & 95 & 59 & 1,6 & 0,04 & 7,5 & 2,6 & 15 & 0,4 & 12,7 & 6,5 \\
\hline Med & 98 & 41 & 35 & 11 & 2,7 & 2,1 & 717 & 145 & 315 & 23 & 13,0 & 7 & 56 & 22,1 & 102 & 44 & 1,0 & 0,04 & 7,1 & 2,6 & 9 & 0,3 & 10,7 & 4,5 \\
\hline De & 74 & 24 & 27 & 21 & 2,7 & 1,2 & 620 & 64 & 169 & 172 & 6,4 & 4 & 68 & 9,1 & 60 & 61 & 2,2 & 0,04 & 5,4 & 1,6 & 145 & 0,3 & 9,9 & 5,6 \\
\hline \multicolumn{25}{|c|}{ Túneles } \\
\hline $\mathrm{n}$ & 14 & 14 & 14 & 14 & 14 & 14 & 14 & 14 & 14 & 14 & 14 & 14 & 14 & 14 & 14 & 14 & 14 & 14 & 14 & 14 & 14 & 13 & 14 & 14 \\
\hline Min & 23 & 10 & 3 & 2 & 0,3 & 0,5 & 35 & 13 & 17 & 100 & 5,9 & 4 & 62 & 8,0 & 7 & 26 & 1,0 & 0,01 & 5,5 & 0,04 & 3 & 0,1 & 2,3 & 0,8 \\
\hline Max & 371 & 35 & 106 & 14 & 5,1 & 3,3 & 1897 & 251 & 388 & 1740 & 17,8 & 21 & 2232 & 33,1 & 190 & 111 & 28,4 & 0,10 & 17,3 & 4,7 & 39 & 0,4 & 19,8 & 11,1 \\
\hline Prom & 78 & 23 & 21 & 6 & 1,6 & 1,6 & 257 & 59 & 106 & 798 & 10,2 & 10 & 440 & 15,0 & 53 & 69 & 6,9 & 0,04 & 11,5 & 0,7 & 11 & 0,2 & 6,1 & 4,1 \\
\hline Med & 42 & 23 & 11 & 6 & 1,0 & 1,3 & 110 & 39 & 84 & 635 & 9,4 & 9 & 323 & 11,9 & 32 & 69 & 3,4 & 0,04 & 11,4 & 0,2 & 8 & 0,2 & 5,1 & 2,8 \\
\hline De & 95 & 7 & 27 & 3 & 1,5 & 0,9 & 489 & 62 & 94 & 591 & 3,5 & 4 & 545 & 7,6 & 55 & 26 & 7,5 & 0,03 & 3,0 & 1,2 & 10 & 0,1 & 4,3 & 3,1 \\
\hline Lc & 0,5 & 1 & 0,4 & 0,5 & 0,05 & 0,1 & 0,2 & 0,5 & 1 & 0,8 & 0,05 & 0,8 & 4 & 0,2 & 0,2 & 1 & 0,08 & 0,005 & 0,05 & 0,01 & 2 & 0,05 & 0,1 & 0,01 \\
\hline
\end{tabular}

n: número de muestras, Min: valor mínimo, Max: valor máximo, Prom: promedio, Med: mediana, De: desviación estándar, Lc: límite de cuantificación. 


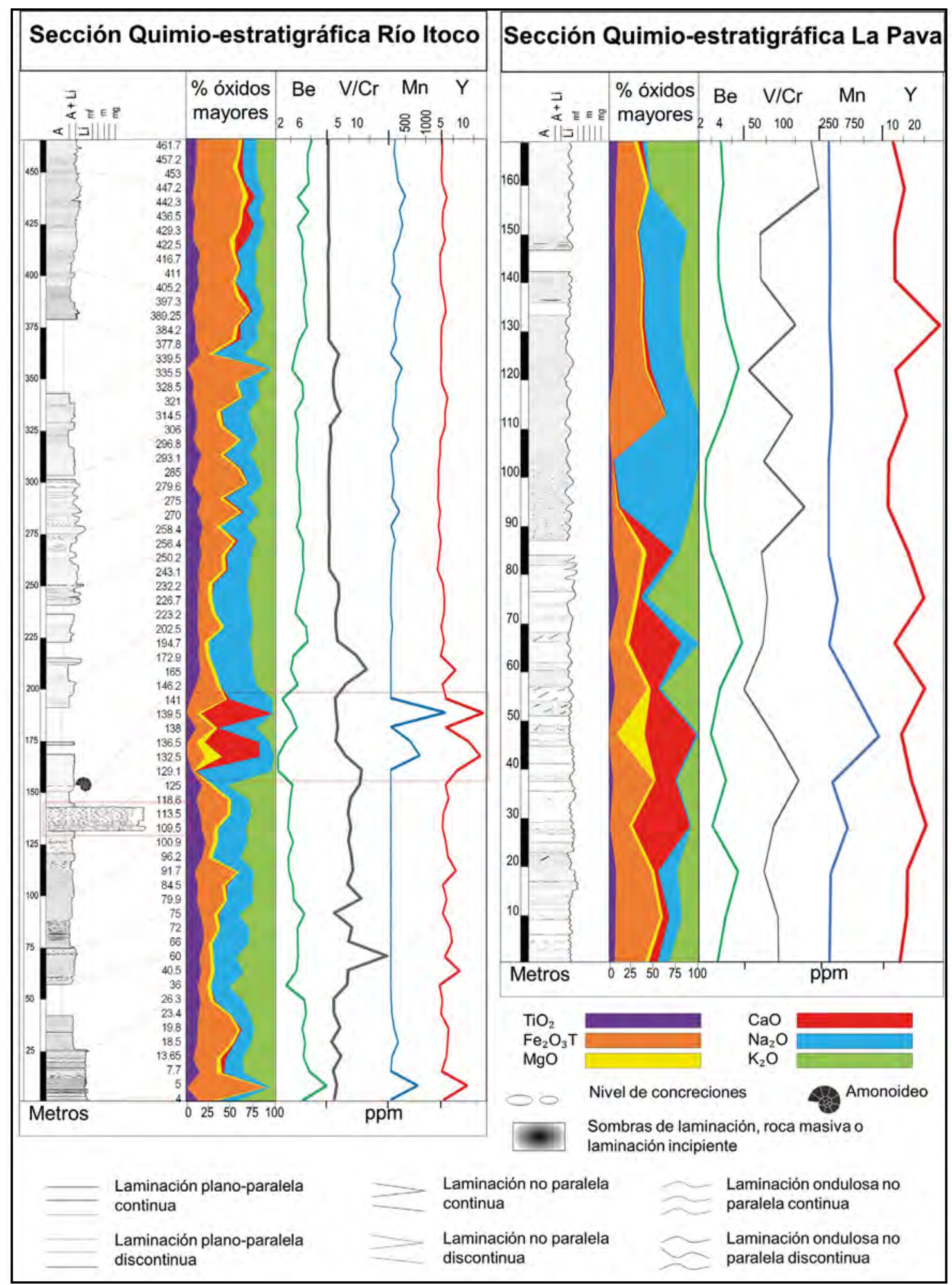

Figura 7. Secciones quimio-estratigráficas de las columnas levantadas en el río Itoco y la quebrada La Pava. En ambas partes las limolitas negras son la litología predominante con esporádicas apariciones de niveles de arcillolitas. Para el caso del río Itoco, las principales variaciones elementales se observan en el intervalo de las albititas brechadas y estratiformes (rectángulo señalado con líneas rojas punteadas: 125-150 m) donde se observan empobrecimientos en los valores de Be, Cr, V y K; con aumento relativo de Ca, Mg, Mn e Y. En la sección de La Pava se observa un aumento generalizado en las concentraciones de Ca y Na, y un comportamiento más variable de los elementos traza. $\mathrm{Fe}_{2} \mathrm{O}_{3} \mathrm{~T}$ : hierro total. 


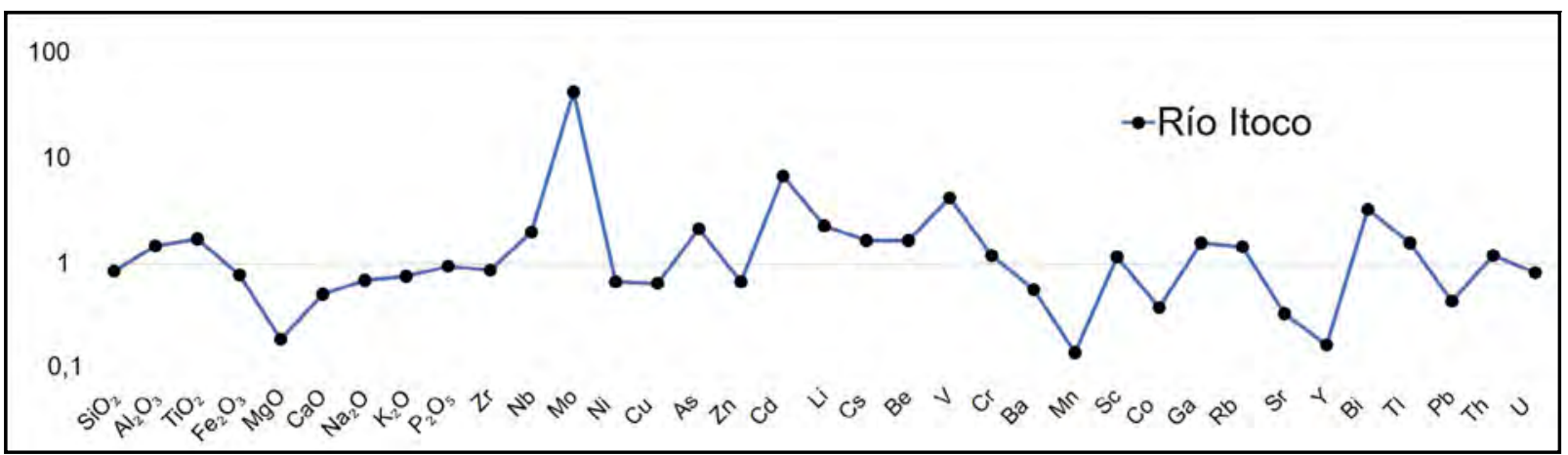

Figura 8. Diagrama multielementos que muestra los valores promedio de la columna del río Itoco normalizados con respecto a la corteza continental superior de Rudnick y Gao (2014). Nótese un enriquecimiento anómalo en los contenidos de Mo, Cd, V y $\mathrm{Bi}$; en contraste con empobrecimientos en Mg, Mn e Y.

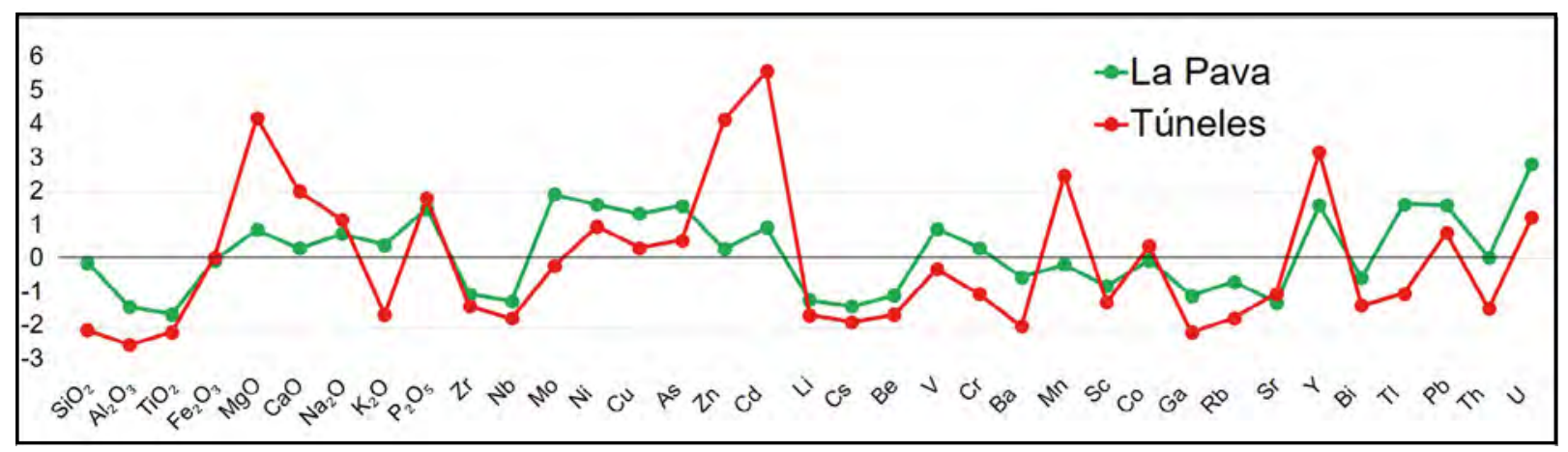

Figura 9. Diagrama comparativo multielementos con los datos de la columna de la quebrada La Pava y las rocas recolectadas en túneles en cercanías a zonas productivas. La escala vertical corresponde a la diferencia entre la desviación estándar de los datos de la sección del río Itoco (valores de fondo). Los valores mayores a 2 (Mg, Ca, Zn, Cd, Mn, Y, U) y menores a -2 (Si, Al, Ti, Ba, $\mathrm{Ga})$ pueden ser considerados como anomalías.

Al graficar los valores promedio de la quebrada La Pava y los túneles, se aprecia un comportamiento similar en la mayoría de los elementos. Sin embargo, las fluctuaciones se acentúan en un mayor grado en las muestras de los túneles. Las variaciones más notables observadas en las muestras de los túneles corresponden con enriquecimientos en los valores de $\mathrm{MgO}, \mathrm{CaO}, \mathrm{P}_{2} \mathrm{O}_{5}, \mathrm{Zn}, \mathrm{Cd}$, Mn e Y; en contraste con empobrecimientos en $\mathrm{SiO}_{2}, \mathrm{Al}_{2} \mathrm{O}_{3}, \mathrm{TiO}_{2}, \mathrm{~K}_{2} \mathrm{O}, \mathrm{Nb}$, $\mathrm{Li}, \mathrm{Cs}, \mathrm{Be}, \mathrm{Ba}$ y $\mathrm{Ga}$. Pocos elementos permanecen inalterados, tal es el caso del $\mathrm{Fe}_{2} \mathrm{O}_{3}$ y el Co, cuyo comportamiento no registra fluctuaciones apreciables en ninguno de los dos grupos; de la misma manera, algunos elementos presentan tendencias no uniformes como por ejemplo el $\mathrm{K}_{2} \mathrm{O}$, Mo, V, Cr, Mn, Tl y Th, los cuales se enriquecen en un grupo y empobrecen en otro. Elementos como el $\mathrm{Na}_{2} \mathrm{O}, \mathrm{Ni}, \mathrm{Cu}, \mathrm{As}, \mathrm{Pb}$ y $\mathrm{U}$ presentan ligeros enriquecimientos en ambos grupos, mientras que $\mathrm{Zr}$, Sc, $\mathrm{Rb}$, Sr y Bi exhiben un empobrecimiento sustancial.

\section{Geoquímica de esmeraldas}

La Tabla 3 muestra los datos de la composición química de 55 esmeraldas de La Pava. En promedio, las concentraciones de $\mathrm{SiO}_{2}$ y $\mathrm{Al}_{2} \mathrm{O}_{3}$ constituyen el 86\%; mientras que el contenido de $\mathrm{BeO}(13,15 \%)$ fue añadido manualmente como valor de referencia, tomado de Groat et al. (2008), con el fin de completar el cierre elemental. De esta manera, las concentraciones medias de otros como elementos como $\mathrm{K}_{2} \mathrm{O}(0,08 \%)$, $\mathrm{CaO}(0,01 \%)$ y $\mathrm{SO}_{3}(0,07 \%)$, no sobrepasan el $1 \%$ del total. El $\mathrm{Na}_{2} \mathrm{O}$ solo fue detectado en 5 muestras con valores particularmente altos (3-6\%), los cuales probablemente se deban a la presencia de inclusiones de albita. Con respecto a los elementos traza, cinco elementos fueron cuantificados en todas las muestras y sus respectivos promedios son: $\mathrm{Cl}$ (1203 ppm), Fe (608 ppm), V (396 ppm), Cr (288 ppm) y Ga (27 ppm). Otros elementos presentes en menores proporciones, con menor frecuencia, incluyen: $\mathrm{Sc}, \mathrm{Ti}, \mathrm{Mn}, \mathrm{Ni}, \mathrm{Cu}$ y 
Zn. Los datos de los elementos cromóforos (V, Cr y Fe) reflejan que el $\mathrm{Fe}$ es el elemento con la concentración más alta, casi superando por el doble a los demás elementos (Cr y V); a su vez, la relación $\mathrm{Cr} / \mathrm{V}$ es en promedio 0,71 e indica la predominancia del $\mathrm{V}$ sobre el Cr. Con el objetivo de visualizar las proporciones relativas de los principales elementos cromóforos de las muestras de La Pava y compararlas con esmeraldas de otras minas, se elaboraron dos diagramas ternarios (Figura 10). Los datos de los otros distritos fueron tomados de la base de datos del Centro de Desarrollo Tecnológico de la Esmeralda Colombiana publicada en
Cedeño et al. (2015). La Figura 10A muestra datos de esmeraldas de los principales distritos en Colombia, y se observa que las muestras de La Pava se agrupan en el campo de esmeraldas ricas en $\mathrm{Fe}$, un comportamiento que difiere sustancialmente de la tendencia general para esmeraldas colombianas. La Figura 10B muestra una comparación con datos de las principales minas del distrito de Muzo-Quípama; aunque la dispersión es amplia, el rango ocupado por las muestras de La Pava muestra una gran similitud con datos de las minas Futuro y Túnel 5.

Tabla 3. Composición química de esmeraldas de La Pava.

\begin{tabular}{|c|c|c|c|c|c|c|c|c|c|c|c|c|c|c|c|c|c|c|c|}
\hline \multirow{2}{*}{ Muestra } & \multicolumn{8}{|c|}{ \% Óxidos (peso) } & \multicolumn{11}{|c|}{ Trazas (ppm) } \\
\hline & BeO* & $\mathrm{SiO}_{2}$ & $\mathrm{Al}_{2} \mathrm{O}_{3}$ & $\mathrm{Na}_{2} \mathrm{O}$ & $\mathrm{K}_{2} \mathrm{O}$ & $\mathrm{CaO}$ & $\mathrm{SO}_{3}$ & Total & Cl & Sc & $\mathbf{T i}$ & V & $\mathrm{Cr}$ & $\mathbf{F e}$ & Mn & $\mathbf{N i}$ & $\mathrm{Cu}$ & Zn & Ga \\
\hline EP-01 & 13,15 & 69,49 & 16,70 & ND & 0,12 & 0,28 & ND & 99,74 & 1349 & ND & 64 & 201 & 221 & 525 & ND & ND & ND & 32 & 16 \\
\hline EP-03 & 13,15 & 69,71 & 16,08 & ND & 0,20 & 0,21 & 0,11 & 99,45 & 3030 & ND & 114 & 496 & 327 & 968 & ND & ND & 37 & 54 & 31 \\
\hline EP-04 & 13,15 & 71,53 & 14,94 & ND & 0,08 & 0,02 & ND & 99,73 & 1086 & 123 & ND & 407 & 292 & 517 & 2 & ND & 15 & ND & 28 \\
\hline EP-05 & 13,15 & 70,14 & 16,25 & ND & 0,09 & 0,06 & 0,03 & 99,73 & 1169 & ND & ND & 429 & 291 & 563 & ND & 8 & 17 & ND & 24 \\
\hline EP-07 & 13,15 & 70,59 & 15,72 & ND & 0,07 & 0,10 & 0,07 & 99,70 & 1115 & 41 & ND & 439 & 397 & 646 & ND & 12 & 19 & ND & 28 \\
\hline EP-08 & 13,15 & 70,48 & 15,89 & ND & 0,07 & 0,16 & ND & 99,75 & 1249 & 113 & 32 & 172 & 158 & 410 & ND & ND & ND & 146 & 18 \\
\hline EP-09 & 13,15 & 69,32 & 17,12 & ND & 0,07 & 0,06 & ND & 99,71 & 1054 & ND & ND & 455 & 305 & 705 & 13 & ND & 20 & 41 & 26 \\
\hline EP-10 & 13,15 & 65,10 & 16,15 & 5,24 & 0,05 & 0,03 & 0,05 & 99,78 & 744 & 108 & ND & 322 & 170 & 562 & ND & ND & ND & 25 & 25 \\
\hline EP-11 & 13,15 & 70,56 & 15,98 & ND & 0,06 & 0,02 & ND & 99,76 & 785 & 94 & ND & 414 & 303 & 510 & ND & ND & 18 & 22 & 25 \\
\hline EP-12 & 13,15 & 70,20 & 16,16 & ND & 0,08 & 0,07 & 0,06 & 99,72 & 1161 & ND & ND & 396 & 273 & 623 & 1,2 & ND & 21 & ND & 25 \\
\hline EP-14 & 13,15 & 70,65 & 15,74 & ND & 0,10 & 0,04 & ND & 99,69 & 1387 & ND & ND & 433 & 303 & 649 & 4,6 & ND & ND & 32 & 29 \\
\hline EP-15 & 13,15 & 69,85 & 15,44 & ND & 0,12 & 0,89 & 0,10 & 99,54 & 1534 & ND & 49 & 439 & 291 & 1269 & 54 & ND & 19 & 368 & 32 \\
\hline EP-16 & 13,15 & 70,23 & 16,20 & ND & 0,08 & 0,05 & ND & 99,71 & 1096 & ND & ND & 447 & 325 & 678 & ND & ND & ND & ND & 35 \\
\hline EP-17 & 13,15 & 70,06 & 16,14 & ND & 0,13 & 0,10 & 0,05 & 99,64 & 1646 & 70 & 50 & 452 & 302 & 662 & 17 & ND & 18 & 116 & 31 \\
\hline EP-18 & 13,15 & 70,45 & 15,93 & ND & 0,11 & 0,04 & 0,05 & 99,72 & 1275 & 94 & ND & 298 & 193 & 525 & ND & 26 & 147 & ND & 29 \\
\hline EP-19 & 13,15 & 66,62 & 15,41 & 4,49 & 0,07 & 0,04 & ND & 99,79 & 862 & ND & ND & 296 & 157 & 537 & ND & ND & 17 & ND & 27 \\
\hline EP-20 & 13,15 & 71,16 & 15,32 & ND & 0,08 & 0,03 & ND & 99,75 & 1082 & ND & ND & 342 & 171 & 609 & ND & ND & 23 & 33 & 32 \\
\hline EP-21 & 13,15 & 70,23 & 16,09 & ND & 0,11 & 0,09 & ND & 99,67 & 1484 & 107 & ND & 471 & 307 & 641 & 8 & ND & 17 & ND & 29 \\
\hline EP-22 & 13,15 & 71,17 & 15,22 & ND & 0,08 & 0,05 & 0,05 & 99,72 & 1038 & 57 & ND & 366 & 315 & 695 & ND & ND & 16 & ND & 26 \\
\hline EP-23 & 13,15 & 70,58 & 15,75 & ND & 0,09 & 0,07 & 0,07 & 99,70 & 1472 & ND & ND & 411 & 286 & 499 & ND & 11 & ND & 28 & 26 \\
\hline EP-24 & 13,15 & 71,03 & 15,36 & ND & 0,07 & 0,12 & ND & 99,73 & 911 & 142 & ND & 447 & 306 & 554 & ND & ND & 21 & 49 & 30 \\
\hline EP-25 & 13,15 & 70,22 & 15,83 & ND & 0,09 & 0,34 & 0,06 & 99,69 & 1105 & ND & ND & 470 & 347 & 786 & ND & ND & ND & 63 & 31 \\
\hline EP-26 & 13,15 & 69,99 & 16,49 & ND & 0,07 & 0,06 & ND & 99,75 & 1032 & ND & ND & 315 & 196 & 585 & ND & 15 & ND & 35 & 23 \\
\hline EP-27 & 13,15 & 70,59 & 15,80 & ND & 0,06 & 0,11 & ND & 99,71 & 1189 & ND & ND & 455 & 318 & 610 & ND & ND & 15 & 32 & 29 \\
\hline EP-30 & 13,15 & 70,08 & 16,36 & ND & 0,06 & 0,04 & 0,07 & 99,75 & 766 & 86 & ND & 361 & 289 & 652 & ND & ND & ND & ND & 25 \\
\hline EP-31 & 13,15 & 69,64 & 16,85 & ND & 0,08 & ND & ND & 99,72 & 1042 & 111 & ND & 466 & 266 & 545 & 7 & 16 & 18 & 93 & 33 \\
\hline EP-32 & 13,15 & 71,08 & 15,31 & ND & 0,09 & 0,09 & ND & 99,72 & 1164 & ND & ND & 431 & 290 & 586 & ND & ND & ND & 45 & 29 \\
\hline EP-33 & 13,15 & 68,89 & 17,59 & ND & 0,06 & 0,13 & ND & 99,81 & 831 & ND & ND & 191 & 223 & 426 & ND & ND & 23 & ND & 16 \\
\hline EP-34 & 13,15 & 69,27 & 17,04 & ND & 0,06 & 0,24 & ND & 99,75 & 792 & 204 & ND & 369 & 285 & 585 & 13 & ND & ND & ND & 24 \\
\hline EP-35 & 13,15 & 70,54 & 16,02 & ND & 0,05 & ND & ND & 99,76 & 597 & 115 & ND & 478 & 327 & 624 & ND & ND & ND & ND & 30 \\
\hline EP-36 & 13,15 & 70,06 & 16,50 & ND & 0,05 & 0,03 & ND & 99,79 & 675 & 112 & ND & 255 & 148 & 578 & ND & 13 & ND & 62 & 28 \\
\hline EP-37 & 13,15 & 69,42 & 16,95 & ND & 0,11 & 0,04 & ND & 99,66 & 1776 & 79 & ND & 439 & 295 & 490 & ND & 13 & 30 & ND & 30 \\
\hline EP-38 & 13,15 & 70,06 & 16,43 & ND & 0,09 & ND & ND & 99,72 & 1093 & 81 & ND & 459 & 327 & 580 & ND & ND & ND & ND & 32 \\
\hline EP-39 & 13,15 & 69,60 & 16,42 & ND & 0,13 & 0,32 & 0,07 & 99,69 & 1515 & ND & ND & 435 & 310 & 585 & ND & ND & 21 & ND & 28 \\
\hline EP-40 & 13,15 & 69,33 & 17,10 & ND & 0,08 & 0,03 & ND & 99,69 & 1312 & 115 & ND & 417 & 295 & 596 & ND & ND & 29 & 35 & 24 \\
\hline EP-41 & 13,15 & 70,09 & 16,39 & ND & 0,05 & 0,07 & ND & 99,74 & 621 & 216 & ND & 452 & 301 & 645 & ND & ND & 19 & 41 & 24 \\
\hline EP-42 & 13,15 & 68,67 & 17,91 & ND & 0,05 & ND & ND & 99,78 & 878 & ND & ND & 384 & 264 & 483 & ND & ND & ND & ND & 21 \\
\hline EP-43 & 13,15 & 70,86 & 15,66 & ND & 0,06 & ND & ND & 99,74 & 1100 & ND & ND & 372 & 186 & 643 & ND & ND & ND & ND & 28 \\
\hline
\end{tabular}


Continuación Tabla 3.

\begin{tabular}{|c|c|c|c|c|c|c|c|c|c|c|c|c|c|c|c|c|c|c|c|}
\hline \multirow{2}{*}{ Muestra } & \multicolumn{8}{|c|}{ \% Óxidos (peso) } & \multicolumn{11}{|c|}{ Trazas (ppm) } \\
\hline & $\mathrm{BeO}^{*}$ & $\mathrm{SiO}_{2}$ & $\mathrm{Al}_{2} \mathrm{O}_{3}$ & $\mathrm{Na}_{2} \mathrm{O}$ & $\mathrm{K}_{2} \mathrm{O}$ & $\mathrm{CaO}$ & $\mathrm{SO}_{3}$ & Total & Cl & Sc & $\mathbf{T i}$ & $\mathbf{v}$ & $\mathrm{Cr}$ & $\mathrm{Fe}$ & Mn & $\mathrm{Ni}$ & $\mathbf{C u}$ & Zn & Ga \\
\hline EP-44 & 13,15 & 70,93 & 15,62 & ND & 0,06 & ND & ND & 99,75 & 1090 & ND & ND & 366 & 209 & 542 & ND & ND & ND & ND & 31 \\
\hline EP-45 & 13,15 & 70,56 & 15,85 & ND & 0,08 & 0,07 & ND & 99,70 & 1388 & 108 & ND & 343 & 176 & 633 & ND & ND & ND & ND & 33 \\
\hline EP-46 & 13,15 & 71,04 & 15,34 & ND & 0,09 & 0,05 & ND & 99,67 & 1502 & 220 & ND & 370 & 226 & 666 & ND & ND & ND & ND & 31 \\
\hline EP-47 & 13,15 & 70,70 & 15,66 & ND & 0,09 & 0,09 & ND & 99,68 & 1354 & 234 & ND & 431 & 294 & 569 & ND & ND & 24 & ND & 27 \\
\hline EP-48 & 13,15 & 69,80 & 16,66 & ND & 0,08 & 0,03 & ND & 99,72 & 1197 & ND & ND & 417 & 302 & 557 & ND & 13 & 19 & 38 & 29 \\
\hline EP-49 & 13,15 & 69,76 & 16,46 & ND & 0,12 & 0,13 & ND & 99,63 & 2020 & ND & ND & 485 & 364 & 595 & ND & ND & ND & ND & 27 \\
\hline EP-50 & 13,15 & 70,47 & 15,73 & ND & 0,07 & 0,06 & 0,08 & 99,55 & 827 & 197 & ND & 813 & 1507 & 723 & ND & ND & 23 & 31 & 54 \\
\hline EP-51 & 13,15 & 67,10 & 16,32 & 3,09 & 0,07 & 0,03 & ND & 99,75 & 994 & ND & ND & 394 & 305 & 507 & ND & ND & 15 & ND & 27 \\
\hline EP-52 & 13,15 & 70,29 & 15,86 & ND & 0,09 & 0,28 & ND & 99,66 & 1373 & ND & ND & 413 & 304 & 788 & ND & 21 & 21 & 59 & 31 \\
\hline EP-53 & 13,15 & 70,91 & 15,51 & ND & 0,11 & 0,03 & ND & 99,70 & 1546 & 97 & ND & 373 & 287 & 432 & ND & ND & 18 & ND & 24 \\
\hline EP-54 & 13,15 & 69,07 & 17,27 & ND & 0,12 & 0,04 & ND & 99,65 & 1695 & ND & ND & 421 & 285 & 761 & ND & ND & ND & ND & 31 \\
\hline EP-55 & 13,15 & 69,02 & 17,23 & ND & 0,16 & 0,03 & ND & 99,59 & 2430 & ND & ND & 437 & 272 & 624 & ND & 15 & 23 & ND & 30 \\
\hline
\end{tabular}

ND: no detectado. *Valor de referencia tomado de Groat et al. (2008).
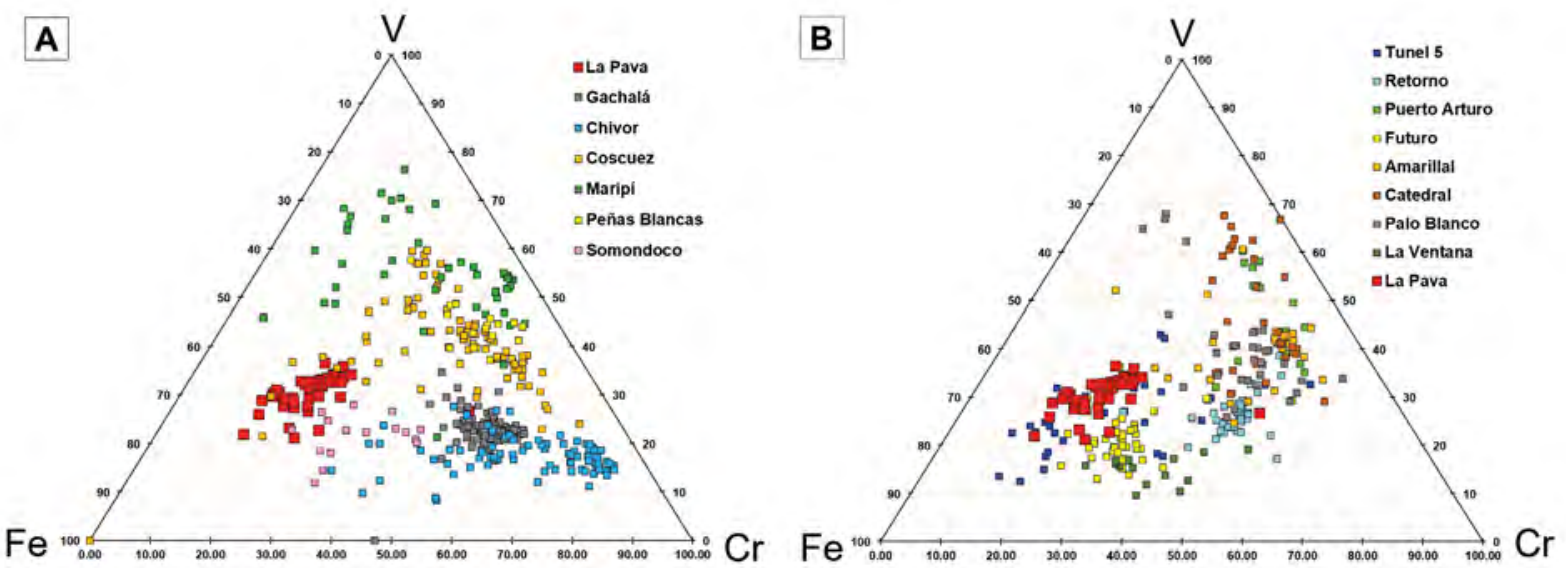

Figura 10. Diagramas ternarios con las concentraciones de elementos cromóforos (Fe-V-Cr) en esmeraldas. A. Comparación entre las esmeraldas de La Pava (distrito Muzo-Quípama) y otros distritos de Colombia. B. Comparación entre esmeraldas de La Pava y otras minas del distrito de Muzo-Quípama. Las muestras de La Pava contienen una mayor proporción de Fe con V>Cr.

\section{Discusión}

\section{Control estructural}

La mineralización de esmeraldas en La Pava muestra una asociación íntima con venas y brechas hidrotermales emplazadas durante un evento deformativo compresional, que ha generado estructuras como el Anticlinal de La Pava, un pliegue por propagación de falla descrito inicialmente por González-Durán et al. (2019). El papel de los anticlinales —particularmente aquellos vinculados a la propagación de fallas inversas- en la formación de yacimientos esmeraldíferos, ha sido documentado por diversos autores en áreas contiguas como Muzo y Coscuez (Branquet et al., 1999; Laumonier et al., 1999; Pignatelli et al., 2015). Existen distintas posturas sobre si existe una relación genética entre las fallas y la mineralización. Branquet et al. (1999) proponen que las fallas de cabalgamiento actúan como zonas de despegue donde se promueve la migración y focalización de fluidos mineralizantes. Bajo este modelo, la sobrepresión de fluidos, en zonas de pliegues por propagación de falla, puede conllevar al eventual brechamiento y mineralización; Cheilletz y Giuliani (1996) describen niveles de albititas brechadas y estratiformes similares a los observados en el río Itoco, y los interpretan como el resultado de la acción de brechamiento tectónico que ha favorecido el metasomatismo. Por otro lado, diversos autores plantean que no existe tal relación y que la mineralización es controlada por un arreglo de estructuras mesoscópicas derivadas de un evento de deformación frágil y penetrativo (Mora et al., 2005; Terraza, 2019). 
No obstante, las características descritas en La Pava favorecen notablemente la intervención de una falla de cabalgamiento en la génesis de la mineralización. Dado que la falla del Águila contribuyó al desarrollo del Anticlinal de La Pava, una estructura que originó deslizamientos flexurales y generación de espacios que eventualmente fueron ocupados por la mineralización en el bloque colgante; esta falla también fue determinante para la posterior exhumación de la Formación Muzo en el área de La Pava. Así mismo, el Anticlinal de la Pava exhibe rasgos de un pliegue disarmónico o asimétrico; una característica descrita por Cheilletz y Giuliani (1996) en estructuras del distrito de Muzo-Quípama. Ante esta configuración, las zonas productivas tenderían a estar confinadas hacia la charnela de los pliegues, y es allí donde las labores de exploración deberían enfocarse.

\section{Implicaciones estratigráficas}

Desde el punto de vista estratigráfico, el horizonte de albititas brechadas constituye un marcador litogeoquímico indiscutible, que por su naturaleza puede ser fácilmente identificado en campañas de perforación, no solamente por su color sino por sus contrastantes características geoquímicas. Además, el nivel de albititas brechado y estratiforme es una característica litoestratigráfica indicativa de la Formación Muzo (Mantilla et al., 2007; Pignatelli et al., 2015; Reyes et al., 2006).

Al comparar los datos geoquímicos de la sección del río Itoco (Formación Muzo y Capotes) con valores disponibles en la literatura de unidades correlacionables, específicamente la Formación Paja, no se observan diferencias significativas en los datos generales. Particularmente, Campos y Roser (2007) reportan enriquecimientos en V, Cr y $\mathrm{Ni}$, y empobrecimientos notables en $\mathrm{CaO}$ y $\mathrm{Na}_{2} \mathrm{O}$ - tendencias que no sobresalen en el río Itoco-; los valores promedio de elementos involucrados en la mineralización (Be: 2,42 ppm (n=18), Y: 33,5 ppm $(\mathrm{n}=24), \mathrm{P}_{2} \mathrm{O}_{5}: 0,25 \%(\mathrm{n}=24)$ y la relación $\mathrm{Cr} / \mathrm{V}$ de 0,35$)$ tampoco exhiben diferencias sustanciales.

Por otra parte, Rivera et al. (2018) reportan valores promedio de algunos elementos traza, entre los cuales se destacan enriquecimientos en $\mathrm{Zn}$, Ni, Cd y una relación $\mathrm{Cr} / \mathrm{V}$ de 0,43 ; además, usaron elementos sensibles a cambios redox para inferir condiciones paleoambientales. Al aplicar estos mismos índices en datos del río Itoco, se obtienen rangos similares, lo cual indicaría que no existieron variaciones composicionales ni de quimio-facies significativas durante la diagénesis de estas rocas. Cabe resaltar que la relación $\mathrm{Cr} / \mathrm{V}$ es anómalamente baja en las rocas de la Formación Paja, en comparación con otras unidades circundantes (Rivera et al., 2018).

\section{Asociaciones minerales}

Por otra parte, las asociaciones paragenéticas muestran grandes similitudes con las descripciones publicadas sobre otras minas de esmeraldas en la región (Banks et al., 2000; Cheilletz et al., 1994; Giuliani et al., 2000; Mantilla et al., 2007; Ottaway et al., 1994; Romero, 1998). Una diferencia notable es la presencia de xenotimo en el ensamblaje de albitización; este mineral también ha sido reportado por Romero et al. (manuscrito en revisión), en la mina Cunas y allí también se encuentra asociado a una etapa de albitización. Distintos minerales portadores de elementos de tierras raras (REE) han sido descritos en zonas esmeraldíferas, entre ellos parisita-(Ce), synchysita-(Ce), bastnasita y monacita (Banks et al., 2000; Cheilletz y Giuliani, 1996; Pignatelli et al., 2015; Romero y Hernández, 1999; Romero, 1998; Toloza et al., 2019; Verbel, 2017); así como de minerales portadores de flúor - fluorita, fluorapatito y parisita-(Ce) - (Banks et al., 2000; Mantilla et al., 2007; Romero, 1998). El papel del flúor es crítico dado que actúa como ligando del berilio (Banks et al., 2000; Verbel, 2017), y promueve la lixiviación, transporte y precipitación de la esmeralda. Además del Be, también se ha planteado que los complejos fluorocarbonados tienen la capacidad de transportar REE y dar origen a la precipitación de fluorocarbonatos como la parisita(Ce) (Verbel, 2017; Williams-Jones et al., 2012). En La Pava, la asociación entre albita, fluorapatito y xenotimo podría sugerir el involucramiento del flúor como ligando durante la albitización. De igual manera, durante la etapa de carbonatización, la presencia de minerales ricos en flúor como fluorapatito, sumado a la alta concentración de carbonatos; podrían indicar una actividad considerable de fluorucarbonatos que actuaron como ligandos, y habrían permitido el enriquecimiento necesario de Be para precipitar esmeraldas. Aunque en este estudio no se identificaron los minerales parisita-(Ce) y fluorita, no se descarta su ocurrencia en La Pava.

Por otro lado, la presencia de monacita autigénica podría indicar que la fuente de REE son las rocas encajantes y que no se requiere de aportes de componentes externos 
para dar origen a la mineralización; una situación similar se podría plantear para el Be, con base en los valores encontrados en las rocas del río Itoco.

\section{Metasomatismo}

El balance de masas realizado con los tres grupos de muestras sugiere que los procesos hidrotermales tuvieron la capacidad de movilizar la mayoría de los elementos analizados (Figura 8 y 9). Las variaciones más notorias, que se aprecian particularmente en las muestras de los túneles, están relacionadas con enriquecimientos en $\mathrm{Mg}, \mathrm{Ca}, \mathrm{Zn}, \mathrm{Cd}, \mathrm{Mn}, \mathrm{Y}, \mathrm{U}$ y empobrecimientos en $\mathrm{Si}, \mathrm{Al}$, Ti, Ba y Ga. Los altos valores de $\mathrm{Mg}$, Ca y $\mathrm{Mn}$ podrían corresponder a la introducción de carbonatos (especialmente dolomita) durante la etapa de carbonatización. El Zn y Cd posiblemente estén alojados en esfaleritas y el $\mathrm{Y}$ en xenotimo. El $\mathrm{U}$ posiblemente este alojado en el xenotimo o en un mineral no identificado. Por otra parte, el empobrecimiento de Al, Ga y Si podría corresponder a la lixiviación que ocurre durante la carbonatización, específicamente cuando los carbonatos disuelven y reemplazan la albita. Del mismo modo, la deficiencia en Ti y Ba podría explicarse por la lixiviación, removilización y posterior precipitación de rutilo y barita (Figura $5 \mathrm{H}$ ). Cabe resaltar que en las muestras del río Itoco (Figura 8), los empobrecimientos de Mg, Mn e $\mathrm{Y}$, podrían sugerir un leve grado de metasomatismo, y que esas rocas no representan la composición exacta y original como se presume.

En la sección del río Itoco, donde el metasomatismo fue pobremente desarrollado, el contenido promedio de Be es de 3,5 ppm; mientras que en la quebrada La Pava es de 2,2 ppm y en los túneles de 1,6 ppm — valores muy similares a los reportados por Giuliani et al. (1999) y Pignatelli et al. (2017) para rocas de diferentes distritos esmeraldíferos colombianos-. Esto indica un porcentaje de lixiviación que oscila entre 37\%$55 \%$ en peso para el Be en zonas de intensa alteración hidrotermal. Giuliani et al. (1999) reportan para la zona productiva de Chivor, un porcentaje de lixiviación de $\mathrm{Be}$ del $\approx 18 \%$ en peso; mientras que Cheilletz y Royant (2001) reportan un valor de hasta $80 \%$; lo cual indica que existen diferencias sustanciales en el grado de lixiviación en los distritos esmeraldíferos, un hecho posiblemente derivado de distintos regímenes de interacción fluido-roca. Además, este parámetro puede resultar útil al momento de realizar estimación de recursos, pues al integrarse con información volumétrica, podría aportar luces sobre la cantidad de Be que precipitaría como esmeralda. Un factor que debe esclarecerse es el porcentaje de Be efectivo que puede llegar a ser precipitado; no todo el Be lixiviado formará esmeraldas, ya que pueden surgir pérdidas en el transporte, así como por la captación por otros minerales como filosilicatos (Cheilletz y Royant, 2001).

Maya et al. (2004) realizan un compendio sobre el estado del arte de la exploración geoquímica en las regiones esmeraldíferas. Se contemplan diferentes escalas y métodos de prospección; para el caso de muestreo de rocas semidetallado, se contemplan los trabajos de Beus y Mineev (1972), PNUD (1975), Beus (1979), Escovar (1979), Mendoza-Parada (1996) y Giuliani et al. (1999); en donde se realizaron balances de masa comparando zonas con alteración hidrotermal vs zonas no alteradas. Los principales indicadores de zonas de lixiviación (considerados como anomalías negativas) son el $\mathrm{Li}, \mathrm{Cs}$, Be, K, Si, Al, Ti, P, REE, $\mathrm{Rb}, \mathrm{Sc}, \mathrm{V}$ y Cr. Por otra parte, las zonas mineralizadas tienden a presentar concentraciones altas de $\mathrm{Na}$, Ca, Mg, Mn, S, y localmente Y, F y P. En los datos de La Pava, el comportamiento del Li, Cs, Be, Si, Al y Ti es consistente con un patrón de lixiviación muy definido; además el $\mathrm{Zr}$, $\mathrm{Nb}$ y Ga también exhiben un comportamiento similar, aunque no hayan sido descritos en otros sectores. Por lo tanto, estos elementos podrían ser empleados como anomalías negativas en la prospección local. Elementos que han mostrado buenos resultados en otras áreas como el $\mathrm{K}, \mathrm{Ba}, \mathrm{Rb}$ y Sc, no son los mejores indicadores en los datos obtenidos de La Pava. En cuanto al enriquecimiento, los valores de $\mathrm{P}_{2} \mathrm{O}_{5}$, Y y U, son los indicadores más consistentes tanto en La Pava como en los túneles; a pesar de que elementos como el $\mathrm{Ca}, \mathrm{Mg}, \mathrm{Mn}, \mathrm{Cd}$ y Zn exhiben la misma tendencia e incluso alcanzan picos elevados, solamente sobresalen a escala muy detallada y por lo tanto deberían tratarse con cautela. Para el caso del Y, debido a su estrecha asociación con el ensamblaje de albitización (a manera de xenotimo); podría constituir un marcador geoquímico fácilmente reconocible mediante análisis petrográficos. Una situación similar ocurre con el fluorapatito; el cual exhibe una relación cercana con las zonas productivas y es un mineral de fácil identificación incluso en campo. Los altos valores de $\mathrm{P}_{2} \mathrm{O}_{5}$ pueden corresponder con la presencia de fluorapatito o xenotimo; además, debido a la similitud entre el comportamiento geoquímico del $\mathrm{P}$ y el $\mathrm{F}$ (sumado a que el apatito alberga $\mathrm{F}$ en su estructura), se infiere que este último elemento podría también convertirse en un indicador geoquímico de zonas mineralizadas a escala local, algo que ha sido propuesto por algunos autores (Beus y Mineev, 1972; Verbel, 2017). 
Otros indicadores geoquímicos como la relación $\mathrm{K} / \mathrm{Na}$, empobrecimientos en $\mathrm{Mo}, \mathrm{Pb}$, Cr y V; altas concentraciones de Na y Ca, no representan parámetros claros para la prospección local en La Pava. A nivel regional algunos elementos ( $\mathrm{Na}$, Sc y Be) exhiben enriquecimientos anómalos que permiten demarcar los distritos esmeraldíferos (Guerrero et al., 2020). Del mismo modo, la relación $\mathrm{K} / \mathrm{Na}$ es un indicador útil para escalas más regionales y en otro tipo de muestras como suelos y aguas (Beus, 1979; Mendoza-Parada, 1996); entre tanto que los valores de Cr y V exhiben una distribución muy aleatoria debido a su fuerte lixiviación y posible incorporación en micas (Cheilletz y Royant, 2001; Giuliani et al., 2000).

Según Giuliani et al. (1999) el empobrecimiento en elementos como $\mathrm{Be}, \mathrm{Cr}, \mathrm{V}, \mathrm{P}_{2} \mathrm{O}_{5}$, Ti, y REE en rocas aledañas a la mineralización, sería el resultado de la distribución parcial dentro del relleno de las venas; donde se encontrarían conformando fases minerales (esmeralda, fluorapatito, rutilo y parisita-(Ce)) o incorporándose como trazas. Este hecho respalda el uso de anomalías negativas y asociaciones minerales en las venas, como criterios de exploración de esmeraldas.

\section{Composición química de las esmeraldas}

Al comparar las concentraciones promedio de Fe de las esmeraldas de La Pava —608 ppm—, con el rango de los distritos colombianos —-772 ppm a $3086 \mathrm{ppm}$ (Cedeño et al., 2015), se evidencia que las muestras de la Pava están por debajo del promedio, es decir, son pobres en Fe. De igual manera sucede con el Cr y el V; para La Pava los valores promedio que se calcularon son 288 ppm de Cr y 389 ppm de V; mientras que los promedios de esmeraldas colombianas oscilan entre 716 ppm a 3922 ppm para V y 1244 ppm a 5012 ppm para Cr. Al observar a primera vista las proporciones relativas de la Figura 10 puede parecer que las esmeraldas de la Pava sean ricas en Fe; sin embargo, las comparaciones realizadas permiten esclarecer que estas muestras son pobres en elementos cromóforos, en particular Cr y V. Como consecuencia, su distribución en el diagrama ternario se localiza en la esquina dominada por $\mathrm{Fe}$; un comportamiento insólito para esmeraldas colombianas, pero recurrente en algunas minas del distrito Muzo-Quípama.

El bajo contenido de elementos cromóforos en las esmeraldas de La Pava puede ser el resultado de: i) bajo contenido de estos elementos en las rocas fuente; ii) cambios significativos en las variables fisicoquímicas (temperatura, presión y composición del fluido mineralizante) que no permitieron su movilización; iii) incorporación en otros minerales. Al comparar las concentraciones de $\mathrm{Cr}$ y $\mathrm{V}$ del río Itoco con datos publicados en otras zonas esmeraldíferas (Beus y Mineev, 1972; Cheilletz y Giuliani, 1996; Pignatelli et al., 2017), no se observan diferencias significativas; una situación similar se observa al revisar los datos de presión y temperatura reportados para esmeraldas de La Pava (Cheilletz y Giuliani, 1996; Giuliani et al., 2000; Jiménez, 2020; Ramírez, 2020; Toloza, 2017). Además, las fluctuaciones en las concentraciones de estos elementos son altas en las muestras de La Pava y los túneles, indicando un alto grado de lixiviación, lo cual excluye la posibilidad de una baja oferta o limitada movilidad durante el metasomatismo. Por otra parte, las micas — particularmente la moscovita— son minerales capaces de captar cantidades sustanciales de Cr y V, alcanzando valores entre $0,1 \%$ a $6 \%$ e incluso mayores (Imai et al., 1980; Morata et al., 2001; Randive et al., 2015), los cuales son claramente mayores a las concentraciones que pueden albergar las esmeraldas (< 2\%) (Groat et al., 2008). En la secuencia paragenética de La Pava, se observan múltiples episodios de cristalización de moscovita, previos a la depositación de la esmeralda (Figura 6), por lo tanto, podría plantearse que los elementos cromóforos fueron en gran manera sustraídos por la moscovita, de tal manera que, al momento de la cristalización de la esmeralda, su disponibilidad era limitada. Cheilletz et al. (1994) soporta este hecho dado que reporta concentraciones de Cr: 208 ppm y V: 892 ppm en micas del distrito Muzo-Quípama.

La relación promedio de $\mathrm{Cr} / \mathrm{V}$ en las esmeraldas $(0,71)$ difiere notablemente con respecto a la de las rocas del río Itoco $(0,51)$ y las zonas mineralizadas $(0,22-0,36)$, hecho que sugiere que hay una mayor captación de $\mathrm{Cr}$ en las esmeraldas en comparación con la disponibilidad en las rocas. Posiblemente, esta relación esté influenciada por una mayor captación de $\mathrm{V}$ en las micas y por lo tanto un enriquecimiento relativo en el fluido mineralizante de Cr. La relación Cr/V en los análisis reportados por Cheilletz et al. (1994) es de 0,23, un valor muy cercano al que se halla en las zonas mineralizadas de La Pava. Este comportamiento también se ha observado en el Cinturón Esmeraldífero Oriental, donde las relaciones $\mathrm{Cr} / \mathrm{V}$ son normalmente mayores a 1 en las esmeraldas, pero menores en las rocas reservorio (Cedeño et al., 2015; Pignatelli et al., 2017). 


\section{Conclusiones}

En la mina La Pava existen una serie de parámetros indicadores de la mineralización de esmeraldas a diferentes escalas. A escala semidetallada: pliegues tipo anticlinal por propagación de fallas inversas; niveles estratigráficos dominados por pelitas, que contengan horizontes albitizados con anomalías geoquímicas que indiquen un alto grado de lixiviación y removilización de una amplia gama de elementos. El metasomatismo de Na y Ca (albitización y carbonatización) es un rasgo típico de bloques mineralizados. A escala local, las anomalías geoquímicas positivas de $\mathrm{Mg}, \mathrm{P}, \mathrm{Cd}, \mathrm{Zn}$, $\mathrm{Mn}$, e Y; negativas de Si, Al, Ti, K, Zr, Nb, Li, Cs, Be, Ba y Ga; en conjunto con la localización de zonas de charnela con presencia de venas, cuyas asociaciones paragenéticas incluyan albita, fluorapatito, xenotimo, calcita, dolomita, rutilo y otras fases ricas en F y REE como parisita-(Ce). Otros minerales como barita, sulfuros y filosilicatos, pueden ocurrir como accesorios y deben tratarse con precaución antes de considerarse como indicadores.

Las esmeraldas de La Pava son pobres en $\mathrm{V}$ y Cr, con concentraciones de $\mathrm{Fe}$ cercanas a las de otras esmeraldas colombianas. La relación $\mathrm{Cr} / \mathrm{V}$ no refleja fielmente la proporción original de estos elementos en las rocas encajantes, lo cual puede ser el resultado de una incorporación diferencial en las micas que modifica la disponibilidad de $\mathrm{Cr}$ y $\mathrm{V}$ al momento de la precipitación de las esmeraldas.

Los parámetros analizados (geoquímica, mineralogía y control estructural) en La Pava exhiben diferencias sustanciales con datos reportados en otras minas y distritos, lo cual demuestra la variabilidad y complejidad de los yacimientos esmeraldíferos. Esto no implica que no se pueda realizar extrapolación de variables, sino más bien que se debe estudiar cada caso en particular para poder establecer los parámetros comunes y así lograr a generar un modelo.

\section{Agradecimientos}

Esta investigación fue realizada gracias a la financiación del Fondo Nacional de la Esmeralda (FEDESMERALDAS). Agradecemos a la empresa Vetas Sierra Alta S.A.S. por el apoyo logístico en campo. El apoyo de Alicia Montes, del Servicio Geológico Colombiano, con los análisis químicos fue de vital importancia. Harry Vargas y Leonardo Paipa realizaron importantes contribuciones conceptuales.
Los aportes de Víctor Torres, Santiago Jiménez, Valeria Ramírez, Sofía Barragán y Camilo Betancur son altamente apreciados.

\section{Referencias}

Banks, D.; Giuliani, G.; Yardley, B.; Cheilletz, A. (2000). Emerald mineralisation in Colombia: Fluid chemistry and the role of brine mixing. Mineralium Deposita, 35(8), 699-713. https://doi.org/10.1007/ s001260050273

Bayona, G. (2018). El inicio de la emergencia en los Andes del norte: una perspectiva a partir del registro tectónico-sedimentológico del Coniaciano al Paleoceno. Revista de la Academia Colombiana de Ciencias Exactas, Físicas y Naturales, 42(165), 364-378. https://doi.org/10.18257/raccefyn.632

Bernet, M.; Urueña, C.; Amaya, S.; Peña, M.L. (2016). New thermo and geochronological constraints on the Pliocene-Pleistocene eruption history of the Paipa-Iza volcanic complex, Eastern Cordillera, Colombia. Journal of Volcanology and Geothermal Research, 327, 299-309. https://doi.org/10.1016/j. jvolgeores.2016.08.013

Beus, A.A. (1979). Sodium - a geochemical indicator of emerald mineralization in the Cordillera Oriental, Colombia. Journal of Geochemical Exploration, 11(2), 195-208. https://doi.org/10.1016/03756742(79)90023-2

Beus, A.; Mineev, D. (1972). Some geological and geochemical features of the Muzo_Cosquez emerald zone, Cordillera Oriental, Colombia. INGEOMINAS, informe 1689, $54 \mathrm{p}$.

Branquet, Y.; Laumonier, B.; Cheilletz, A.; Giuliani, G. (1999). Emeralds in the Eastern Cordillera of Colombia: Two tectonic settings for one mineralization. Geology, 27(7), 597-600. https:// doi.org/10.1130/0091-7613(1999)027<0597:EITE $\mathrm{CO}>2.3 . \mathrm{CO} ; 2$

Campos, N.O.; Roser, B.P. (2007). Geochemistry of black shales from the Lower Cretaceous Paja Formation, Eastern Cordillera, Colombia: Source weathering, provenance, and tectonic setting. Journal of South American Earth Sciences, 23(4), 271-289. https:// doi.org/10.1016/j.jsames.2007.02.003 
Cedeño, C.J.; Jiménez, J.F.; Herreño, J.H.; Fortaleché, D. (2015). Progress on the study of parameters related to the origin of Colombian emeralds. Color, World Emer, (Special Issue), 88-97.

Cheilletz, A.; Feraud, G.; Giuliani, G.; Rodriguez, C.T. (1994). Time-pressure and temperature constraints on the formation of Colombian emeralds; an ${ }^{40} \mathrm{Ar} /$ ${ }^{39} \mathrm{Ar}$ laser microprobe and fluid inclusion study. Economic Geology, 89(2), 361-380. https://doi. org/10.2113/gsecongeo.89.2.361

Cheilletz, A.; Giuliani, G. (1996). The genesis of Colombian emeralds: A restatement. Mineralium Deposita, 31(5), 359-364. https://doi.org/10.1007/ BF00189183

Cheilletz, A.; Royant, J.C. (2001). The black-shale hosted Colombian emerald deposits: a synthetic genetic model with emphasis on the source of beryllium. In: A. Piestrzynski (ed.). Mineral Deposits at the Beginning of the 21st Century (pp. 43-45). A.A. Balkema.

Escovar, R. (1979). Geología y geoquímica de las minas de esmeraldas de Gachalá, Cundinamarca. Boletín Geológico, 22(3), 117-153.

Folk, R.L. (1980). Petrology of sedimentary rocks. Hemphill Publishing Company.

Gandhi, S.M.; Sarkar, B.C. (2016). Geochemical Exploration. In: S.M. Gandhi; B.C. Sarkar (eds.). Essentials of mineral exploration and evaluation (pp. 125-158). Chapter 6. Elsevier. https://doi. org/10.1016/B978-0-12-805329-4.00013-2

Giuliani, G.; Cheilletz, A.; Arboleda, C.; Carrillo, V.; Rueda, F.; Baker, J.H. (1995). An evaporitic origin of the parent brines of Colombian emeralds: fluid inclusion and sulphur isotope evidence. European Journal of Mineralogy, 7(1), 151-165. https://doi. org/10.1127/ejm/7/1/0151

Giuliani, G.; Bourlès, D.; Massot, J.; Siame, L. (1999). Colombian emerald reserves inferred from leached beryllium of their host black shale. Exploration and Mining Geology, 8(1), 109-116.

Giuliani, G.; France-Lanord, C.; Cheilletz, A.; Coget, P.; Branquet, Y.; Laumomnier, B. (2000). Sulfate reduction by organic matter in Colombian emerald deposits: chemical and stable isotope $(\mathrm{C}, \mathrm{O}, \mathrm{H})$ evidence. Economic Geology, 95(5), 1129-1153. https://doi.org/10.2113/gsecongeo.95.5.1129

Giuliani, G.; Groat, L.A.; Marshall, D.; Fallick, A.E.; Branquet, Y. (2019). Emerald deposits: A review and enhanced classification. Minerals, 9(2). https://doi.org/10.3390/min9020105

González-Durán, A.; García, J.; Bonilla, G.; Cedeño, C.; Angarita, L. (2019). Geology of the La Pava emerald mine, Colombia. 15th SGA Biennial Meeting, Glasgow, Scotland.

Groat, L.A.; Giuliani, G.; Marshall, D.D.; Turner, D. (2008). Emerald deposits and occurrences: A review. Ore Geology Reviews, 34(1-2), 87-112. https://doi.org/10.1016/j.oregeorev.2007.09.003

Guerrero, J.; Mejía-Molina, A.; Osorno, J. (2020). Detrital U-Pb provenance, mineralogy, and geochemistry of the Cretaceous Colombian backarc basin. In: J. Gómez, A.O. Pinilla-Pachon (ed.). The Geology of Colombia (pp. 261-297). Volume 2, Chapter 8. Servicio Geológico Colombiano. https://doi.org/10.32685/pub.esp.36.2019.08

Hewton, M.L.; Marshall, D.D.; Ootes, L.; Loughrey, L.E.; Creaser, R.A. (2013). Colombian-style emerald mineralization in the northern Canadian Cordillera: integration into a regional Paleozoic fluid flow regime. Canadian Journal of Earth Sciences, 50(8), 857-871. https://doi.org/10.1139/ cjes-2012-0128

Horton, B.K.; Parra, M.; Mora, A. (2020). Construction of the Eastern Cordillera of Colombia: Insights from the Sedimentary Record. In: J. Gómez, D. Mateus-Zabala (ed.). The Geology of Colombia (pp. 67-88). Volume 3, Chapter 3. Servicio Geológico Colombiano. https://doi.org/10.32685/ pub.esp.37.2019.03

Imai, N; Lee, H.K.; Machida, M. (1980). Vanadiumbearing green mica from the Jangsan Quartzite in the Janggun mine area, Republic of Korea. Clay Science, 5(5), 221-236. https://doi.org/10.11362/ jcssjclayscience1960.5.221

Jiménez, S. (2020). Planteamiento y caracterización de la secuencia paragenética a través de análisis petrográfico, inclusiones fluidas y espectroscopía Raman de la mineralización presente en el túnel de la mina La Pava municipio de Quípama, Boyacá. 
Thesis, Universidad Nacional de Colombia, Bogotá, Colombia.

Kammer, A.; Piraquive, A.; Gómez, C.; Mora, A.; Velásquez, A. (2020). Structural Styles of the Eastern Cordillera of Colombia. In: J. Gómez, D. Mateus-Zabala (ed.). The Geology of Colombia (pp. 143-183). Volume 3, Chapter 6. Servicio Geológico Colombiano. https://doi.org/10.32685/ pub.esp.37.2019.06

Laumonier, B.; Branquet, Y.; Cheilletz, A.; Giuliani, G. (1999). Structural setting and age of the Colombian emerald deposits: implications for the tectonic evolution of the Cordillera Oriental. Fourth ISAG, 2p.

Mantilla, L.C.; Silva, A.; Serrano, J; Conde, J.; Gomez, C.; Ramirez, J.; Meza, J.; Pelayo, Y.; Ortega, L.; Plata, L.; Peña, E. (2007). Investigación petrográfica y geoquímica de las sedimentitas del cretácico inferior (K1) y sus manifestaciones hidrotermales asociadas; planchas 169, 170, 189, 190 (Cordillera Oriental): implicaciones en la búsqueda de esmeraldas. Acuerdo Específico 02 de 2006. INGEOMINAS-Universidad Industrial de Santander (UIS). Comprende informe, 349p.

Maya, M.; Buenaventura, J.; Salinas, R. (2004). Estado del conocimiento de la exploración de esmeraldas en Colombia. INGEOMINAS. Comprende informe, 90p.

Mendoza-Parada, J. (1996). Anotaciones geoquímicas para exploración de esmeraldas en la región Muzo-Coscuez con base en la relación $\mathrm{Na} / \mathrm{K}$ y elementos traza. Geología Colombiana, 21, 8998.

Mora, A; Reyes, G; Valencia, A. (2005). Levantamiento de información estratigráfica y estructural de los cinturones esmeraldíferos de la Cordillera Oriental. INGEOMINAS, informe técnico.

Mora, A. (2007). Inversion tectonics and exhumation processes in the Eastern Cordillera of Colombia. Ph.D. Thesis, Universidad de Potsdam, Potsdam, Alemania.

Morata, D.; Higueras, P.; Domínguez-Bella, S.; Parras, J.; Velasco, F.; Aparicio, P. (2001). Fuchsite and other Cr-rich phyllosilicates in ultramafic enclaves from the Almadén mercury mining district, Spain. Clay Minerals, 36(3), 345-354. https://doi.org/10.1180/000985501750539445

Moreno, G.; Terraza, R.; Montoya, D. (2009). Geología del Cinturón Esmeraldífero Oriental (CEOR). Boletín de Geología, 31(2), 51-67.

Ottaway, T.L.; Wicks, F.J.; Bryndzia, L.T.; Kyser, T.K.; Spooner, E.T. (1994). Formation of the Muzo hydrothermal emerald deposit in Colombia. Nature, 369(16), 552-554. https://doi. org/10.1038/369552a0

Pignatelli, I.; Giuliani, G.; Ohnenstetter, D.; Agrosi, G.; Mathieu, S.; Morlot, C.; Branquet, Y. (2015). Colombian Trapiche Emeralds: Recent Advances in Understanding Their Formation. Gems \& Gemology, 51(3), 222-259.

Pignatelli, I.; Giuliani, G.; Morlot, C.; Rouer, O.; Claiser, N.; Chatagnier, P.Y.; Goubert, D. (2017). Recent advances in understanding the similarities and differences of Colombian euclases. The Canadian Mineralogist, 55(4), 799-820. https:// doi.org/10.3749/canmin.1700011

PNUD. (1975). Proyecto Esmeraldas. INGEOMINAS, programa de las Naciones Unidas para el desarrollo. PNUD Informe técnico final, Informe 1683, Colombia.

Ramírez, V. (2020). Secuencia paragenética presente en el túnel "Cromo-Pomponio-Santodomingo" de la mina La Pava municipio de Quípama, Boyacá obtenida a partir de la caracterización petrográfica, análisis de inclusiones fluidas y espectroscopía Raman. Thesis, Universidad Nacional de Colombia, Bogotá, Colombia.

Randive, K.R.; Korakoppa, M.M.; Muley, S.V.; Varade, A.M.; Khandare, H.W.; Lanjewar, S.G.; Tiwari, R.R.; Aradhi, K.K. (2015). Paragenesis of Cr-rich muscovite and chlorite in green-mica quartzites of Saigaon-Palasgaon area, Western Bastar Craton, India. Journal of Earth System Science, 124(1), 213-225. https://doi.org/10.1007/s12040014-0514-0

Reyes, G.; Montoya, D.; Terraza, R.; Fuquen, J.; Mayorga, M.; Gaona, T. (2006). Geología del Cinturón Esmeraldífero Occidental Planchas 169, 170, 189 y 190. INGEOMINAS. Comprende mapa a escala 1:100000 e informe, 114p. 
Rivera, H.A.; Le Roux, J.P.; Sánchez, L.K.; MariñoMartínez, J.E.; Salazar, C.; Barragán, J.C. (2018). Palaeoredox conditions and sequence stratigraphy of the Cretaceous storm-dominated, mixed siliciclastic-carbonate ramp in the Eastern Cordillera Basin (Colombia): Evidence from sedimentary geochemical proxies and facies analysis. Sedimentary Geology, 372, 1-24. https:// doi.org/10.1016/j.sedgeo.2018.05.003

Romero, F.E. (1998). Esmeraldas colombianas: mineralogia, geologia e gênese. Ph.D. Thesis, Universidade de Sao Paulo, Brazil. https://doi. org/10.11606/T.44.1998.tde-11112015-154809

Romero, F.H.; Hernández, O. (1999). Características mineralógicas e inclusiones fluidas de las esmeraldas del municipio de San Antonio de Yacopí, Cundinamarca, Colombia. Geología Colombiana, 24, 149-158.

Romero, F.H.; González-Durán, A.F.; GarcíaToloza, T.; Rotlewicz, J.; Cedeño-Ochoa, C.J.; Alvarado-González, H.R.; Angarita-Sarmiento, L.G. (manuscrito en revisión). Mineralogy and fluid inclusions of the Cunas emeralds, Maripí, Colombia. Earth Sciences Research Journal.

Rudnick, R.L.; Gao, S. (2014). Composition of the Continental Crust. In: H. Holland; K. Turekian (eds.). Treatise on Geochemistry (pp. 1-51). Vol. 4. 2nd edition, Elsevier. https://doi.org/10.1016/ B978-0-08-095975-7.00301-6

Teixell, A.; Ruiz, J.C.; Teson, E.; Mora, A. (2015). The Structure of an inverted back-arc rift: insights from a transect across the Eastern Cordillera of Colombia near Bogota. In: C. Bartolini, P. Mann (eds.). Petroleum Geology and Potential of the Colombian Caribbean Margin (pp. 99-113). Vol. 108, American Association of Petroleum Geologists. https://doi. org/10.1306/13531947M1083650
Terraza, R. (2019). Notas sobre el contexto tectonoestratigráfico de formación de las esmeraldas colombianas. Boletín Geológico, 45, 37-48. https://doi.org/10.32685/0120-1425/ boletingeo.45.2019.486

Toloza, G.J. (2017). Estudio de inclusiones fluidas en esmeralda colombiana "tras la firma química" Boyacá (Colombia). Thesis, Universidad Nacional de Colombia-Bogotá, Colombia.

Toloza, G.J.; González-Durán, A.F.; Hernández, J.D.; Cedeño, C.J.; Angarita, L.G.; Morales, A.; Zamora, J.; Alvarado, H. (2019). Ocurrencia de Parisita y Synchysita en Chivor, Cinturón Esmeraldífero Oriental de Colombia. XVII Congreso Colombiano de Geología, Santa Marta, Colombia.

UPME. (2020). Cifras y publicaciones de producción de esmeraldas en Colombia. https://www1. upme.gov.co/simco/Cifras-Sectoriales/Paginas/ esmeraldas.aspx

Vásquez, M.; Altenberger, U.; Romer, R.L.; Sudo, M.; Moreno-Murillo, J.M. (2010). Magmatic evolution of the Andean Eastern Cordillera of Colombia during the Cretaceous: Influence of previous tectonic processes. Journal of South American Earth Sciences, 29(2), 171-186. https:// doi.org/10.1016/j.jsames.2009.02.003

Verbel, Á. (2017). Mineralogía de elementos de tierras raras en las mineralizaciones esmeraldíferas colombianas. M.Sc. Thesis, Universidad Nacional de Colombia, Bogotá, Colombia.

Williams-Jones, A.; Migdisov, A.; Samson, I. (2012). Hydrothermal Mobilisation of the Rare Earth Elements-a Tale of "Ceria" and "Yttria". Elements, 8(5), 355-360. https://doi.org/10.2113/ gselements.8.5.355

Fecha de recibido: 27 de octubre de 2020

Fecha de aprobado: 6 de abril de 2021 


\section{Anexo 1}

Resultados de los análisis composicionales de roca total mediante fluorescencia de rayos X (FRX) y gravimetría (Grav), expresados en \% en peso y ppm.

\begin{tabular}{|c|c|c|c|c|c|c|c|c|c|c|c|c|c|c|c|c|c|c|}
\hline \multirow{2}{*}{ Código } & \multicolumn{9}{|c|}{ Resultados Elementos Mayores (\% en peso) por FRX } & \multirow{2}{*}{$\begin{array}{c}\text { Grav } \\
\text { LOI }\end{array}$} & \multirow[b]{2}{*}{ Total } & \multicolumn{7}{|c|}{ ppm (FRX) } \\
\hline & $\mathrm{SiO}_{2}$ & $\mathrm{Al}_{2} \mathrm{O}_{3}$ & $\mathrm{TiO}_{2}$ & $\mathrm{Fe}_{2} \mathrm{O}_{3} \mathrm{~T}$ & MgO & $\mathrm{CaO}$ & $\mathrm{Na}_{2} \mathrm{O}$ & $\mathrm{K}_{2} \mathrm{O}$ & $\mathbf{P}_{2} \mathrm{O}_{5}$ & & & $\mathrm{Zr}$ & Ge & Nb & Mo & Sn & Sb & Hf \\
\hline It-1 & 61,30 & 25,58 & 1,27 & 1,16 & 0,33 & 0,10 & 1,75 & 3,15 & $<0,024$ & 5,12 & 99,76 & 179 & 2 & 25 & 55 & 8 & $<12$ & $<8$ \\
\hline It-2 & 64,25 & 23,95 & 1,01 & 0,69 & 0,31 & 0,11 & 1,68 & 3,02 & $<0,024$ & 4,79 & 99,81 & 153 & 2 & 20 & 52 & $<8$ & $<12$ & $<8$ \\
\hline It-3 & 38,97 & 16,60 & 0,55 & 31,61 & 0,49 & 0,17 & 1,24 & 2,30 & 0,114 & 7,69 & 99,73 & 94 & $<2$ & 12 & 26 & 12 & $<12$ & 19 \\
\hline It-4 & 59,56 & 25,95 & 1,34 & 1,69 & 0,51 & 0,20 & 1,99 & 3,04 & 0,054 & 5,42 & 99,75 & 166 & 4 & 27 & 32 & $<8$ & $<12$ & $<8$ \\
\hline It-5 & 60,97 & 25,09 & 0,72 & 2,26 & 0,36 & 0,48 & 1,61 & 3,16 & $<0,024$ & 5,12 & 99,77 & 109 & 2 & 14 & 110 & $<8$ & $<12$ & $<8$ \\
\hline It-6 & 61,85 & 23,32 & 1,16 & 3,59 & 0,29 & 0,11 & 1,77 & 2,65 & 0,050 & 4,97 & 99,76 & 172 & 2 & 26 & 36 & 9 & 15 & $<8$ \\
\hline It-7 & 63,08 & 19,04 & 1,29 & 4,48 & 0,26 & 0,20 & 1,39 & 2,33 & 0,174 & 7,53 & 99,77 & 215 & $<2$ & 30 & 56 & 10 & 13 & 9 \\
\hline It-8 & 57,15 & 24,16 & 1,33 & 3,24 & 0,29 & $<0,10$ & 1,98 & 2,63 & 0,164 & 8,74 & 99,68 & 187 & $<2$ & 29 & 62 & $<8$ & $<12$ & 9 \\
\hline $\begin{array}{l}\text { It-9 } \\
\end{array}$ & 60,95 & 25,11 & 1,18 & 0,78 & 0,28 & 0,11 & 2,23 & 2,54 & $<0,024$ & 6,64 & $\begin{array}{l}9,82 \\
\end{array}$ & 167 & 3 & 25 & 79 & $<8$ & 14 & $<8$ \\
\hline It-10 & 68,39 & 14,65 & 0,50 & 0,39 & 0,17 & $<0,10$ & 0,78 & 1,96 & $<0,024$ & 12,86 & 99,70 & 98 & 2 & 11 & 138 & $<8$ & 13 & $<8$ \\
\hline It-11 & 66,25 & 22,24 & 1,06 & 0,66 & 0,26 & $<0,10$ & 2,01 & 2,17 & 0,063 & 5,01 & 99,72 & 122 & $<2$ & 19 & 25 & $<8$ & 12 & $<8$ \\
\hline It-12 & 57,29 & 26,54 & 1,08 & 0,90 & 0,27 & $<0,10$ & 1,80 & 3,22 & $<0,024$ & 8,33 & 99,43 & 118 & 3 & 15 & 119 & $<8$ & 18 & $<8$ \\
\hline It-13 & 65,59 & 23,04 & 1,17 & 0,39 & 0,25 & $<0,10$ & 2,40 & 1,84 & $<0,024$ & 4,99 & 99,67 & 146 & 3 & 24 & 8 & $<8$ & $<12$ & $<8$ \\
\hline It-14 & 58,85 & 22,85 & 1,32 & 1,02 & 0,23 & $<0,10$ & 2,19 & 1,93 & 0,049 & 11,16 & 99,60 & 158 & 2 & 22 & 118 & $<8$ & 22 & $<8$ \\
\hline It-15 & 66,35 & 18,92 & 0,76 & 1,96 & 0,20 & $<0,10$ & 1,90 & 1,50 & 0,047 & 8,03 & 99,67 & 153 & 4 & 16 & 137 & $<8$ & 23 & $<8$ \\
\hline It-16 & 59,18 & 22,79 & 1,04 & 2,09 & 0,27 & 0,14 & 2,20 & 2,00 & 0,040 & 9,91 & 99,66 & 131 & 4 & 17 & 108 & $<8$ & 22 & $<8$ \\
\hline It-17 & 58,45 & 19,08 & 0,89 & 4,15 & 0,26 & $<0,10$ & 1,53 & 2,11 & 0,206 & 12,92 & 99,60 & 132 & 3 & 14 & 368 & $<8$ & 35 & $<8$ \\
\hline It-18 & 59,48 & 21,47 & 1,02 & 0,35 & 0,26 & $<0,10$ & 1,78 & 2,17 & $<0,024$ & 13,06 & 99,59 & 141 & $<2$ & 16 & 60 & $<8$ & 23 & $<8$ \\
\hline It-19 & 61,45 & 24,24 & 1,52 & 0,63 & 0,34 & $<0,10$ & 2,30 & 2,18 & 0,056 & 6,93 & 99,65 & 165 & 3 & 23 & 21 & $<8$ & 21 & $<8$ \\
\hline It-20 & 67,51 & 17,35 & 0,90 & 0,71 & 0,21 & $<0,10$ & 1,54 & 1,67 & $<0,024$ & 9,77 & 99,66 & 129 & 2 & 16 & 119 & $<8$ & 24 & $<8$ \\
\hline It-21 & 58,68 & 20,68 & 1,31 & 2,49 & 0,29 & $<0,10$ & 1,86 & 2,18 & $<0,024$ & 12,21 & 99,70 & 172 & 3 & 20 & 103 & $<8$ & 35 & $<8$ \\
\hline It-22 & 70,36 & 16,77 & 0,75 & 2,30 & 0,25 & $<0,10$ & 1,28 & 1,92 & $<0,024$ & 6,08 & 99,71 & 125 & 2 & 14 & 224 & $<8$ & 27 & $<8$ \\
\hline It-23 & 65,59 & 22,43 & 1,33 & 0,67 & 0,33 & $<0,10$ & 1,08 & 4,00 & 0,103 & 3,94 & 99,47 & 204 & 2 & 20 & 8 & $<8$ & $<12$ & 9 \\
\hline It-24 & 65,39 & 18,80 & 0,80 & 0,21 & 0,10 & 0,20 & 9,29 & 0,55 & $<0,024$ & 4,30 & 99,64 & 114 & 3 & 14 & 63 & $<8$ & 13 & $<8$ \\
\hline It-25 & 36,41 & $\begin{array}{l}11,19 \\
\end{array}$ & 0,49 & 6,48 & 5,98 & 13,48 & 5,14 & 0,49 & 0,128 & $\begin{array}{l}17,81 \\
\end{array}$ & 97,60 & 77 & $<2$ & 13 & 6 & $<8$ & $<12$ & $<8$ \\
\hline It-26 & 39,40 & 12,66 & 0,49 & 2,88 & 2,64 & 17,44 & 3,50 & 1,70 & 0,211 & 15,85 & 96,77 & 90 & $<2$ & 12 & 6 & $<8$ & $<12$ & $<8$ \\
\hline It-27 & 23,67 & 5,21 & 0,20 & 4,63 & 2,13 & 32,75 & 0,21 & 1,08 & 0,079 & 23,59 & 93,55 & 55 & $<2$ & 11 & 5 & 12 & $<12$ & 15 \\
\hline It-28 & 56,37 & 17,69 & 0,82 & 6,19 & 0,26 & 0,53 & 7,50 & 0,58 & 0,318 & 9,54 & 99,80 & 154 & $<2$ & 19 & 7 & $<8$ & $<12$ & 14 \\
\hline It-29 & 56,98 & 26,63 & 0,90 & 1,50 & 0,31 & 0,11 & 3,27 & 1,62 & 0,084 & 8,42 & $\begin{array}{l}9,82 \\
\end{array}$ & 220 & - & - & - & - & - & - \\
\hline It-30 & 55,81 & 27,26 & 0,92 & 1,79 & 0,31 & $<0,10$ & 3,25 & 1,67 & $<0,024$ & 8,68 & 99,69 & 124 & 3 & 23 & 24 & $<8$ & 13 & $<8$ \\
\hline $\begin{array}{l}\text { It-31 } \\
\end{array}$ & 62,65 & 20,92 & 0,92 & 0,71 & 0,25 & $<0,10$ & 2,35 & 1,41 & $<0,024$ & 10,37 & 99,58 & 139 & 3 & 21 & 141 & $<8$ & 13 & $<8$ \\
\hline It-32 & 58,97 & 25,24 & 0,87 & 0,55 & 0,27 & $<0,10$ & 3,03 & 1,63 & $<0,024$ & 9,07 & 99,63 & 118 & 2 & 21 & 58 & $<8$ & 15 & $<8$ \\
\hline It-33 & 57,01 & 28,43 & 1,08 & 0,43 & 0,34 & $<0,10$ & 3,30 & 2,09 & $<0,024$ & 7,09 & $\begin{array}{l}99,77 \\
\end{array}$ & 120 & 2 & 25 & 11 & $<8$ & $<12$ & $<8$ \\
\hline It-34 & 54,12 & 27,61 & 1,19 & 2,35 & 0,35 & $<0,10$ & 2,91 & 2,25 & 0,042 & 8,88 & 99,70 & 154 & 3 & 29 & 12 & $<8$ & $<12$ & $<8$ \\
\hline It-35 & 59,37 & 25,37 & 0,97 & 1,08 & 0,30 & $<0,10$ & 2,81 & 1,89 & 0,027 & 7,99 & 99,81 & 112 & 3 & 24 & 15 & $<8$ & 13 & $<8$ \\
\hline It-36 & 59,55 & 26,03 & 0,87 & 0,76 & 0,30 & $<0,10$ & 2,72 & 1,91 & 0,047 & 7,52 & 99,71 & 105 & 3 & 21 & 20 & $<8$ & 15 & $<8$ \\
\hline It-37 & 56,44 & 28,23 & 1,09 & 0,74 & 0,38 & 0,12 & 2,80 & 2,36 & $<0,024$ & 7,64 & 99,80 & 121 & $<2$ & 25 & 13 & $<8$ & $<12$ & $<8$ \\
\hline It-38 & 55,92 & 25,96 & 1,27 & 2,47 & 0,36 & 0,19 & 2,32 & 2,51 & 0,123 & 8,66 & 99,78 & 195 & 3 & 31 & 5 & $<8$ & $<12$ & 10 \\
\hline It-39 & 60,06 & 23,70 & 1,42 & 1,82 & 0,33 & 0,13 & 2,22 & 2,25 & 0,098 & 7,75 & 99,78 & 272 & 2 & 33 & 2 & 8 & $<12$ & 9 \\
\hline It-40 & 59,77 & 21,89 & 1,48 & 3,76 & 0,33 & 0,28 & 2,04 & 2,10 & 0,157 & 7,99 & 99,80 & 310 & $<2$ & 32 & $<2$ & 9 & $<12$ & 9 \\
\hline It-41 & 60,88 & 24,11 & 1,37 & 1,08 & 0,33 & $<0,10$ & 2,10 & 2,31 & 0,070 & 7,49 & 99,74 & 241 & 3 & 31 & 2 & 8 & $<12$ & 8 \\
\hline It-42 & 60,81 & 20,57 & 1,40 & 5,08 & 0,32 & 0,26 & 1,93 & 1,96 & 0,199 & 7,29 & 99,82 & 305 & $<2$ & 31 & $<2$ & 9 & $<12$ & 9 \\
\hline It-43 & 59,46 & 24,53 & 1,41 & 1,66 & 0,33 & 0,19 & 2,13 & 2,40 & 0,202 & 7,46 & $\begin{array}{l}99,77 \\
\end{array}$ & 273 & $<2$ & 32 & 2 & 9 & $<12$ & 9 \\
\hline It-44 & 53,64 & 23,01 & 1,05 & 8,71 & 0,29 & 0,14 & 2,41 & 1,99 & 0,194 & 8,46 & 99,89 & 213 & $<2$ & 25 & 2 & 10 & $<12$ & $<8$ \\
\hline It-45 & 59,19 & 21,71 & 1,29 & 4,96 & 0,29 & 0,16 & 2,02 & 2,01 & 0,196 & 7,99 & 99,82 & 276 & $<2$ & 30 & 2 & 10 & $<12$ & 10 \\
\hline It-46 & 59,14 & 24,61 & 1,42 & 1,71 & 0,34 & 0,11 & 2,28 & 2,38 & 0,108 & 7,74 & 99,84 & 227 & 3 & 32 & 2 & $<8$ & $<12$ & 9 \\
\hline It-47 & 60,00 & 21,76 & 0,89 & 5,22 & 0,29 & $<0,10$ & 2,03 & 1,99 & 0,108 & 7,44 & 99,73 & 131 & $<2$ & 21 & 15 & 9 & $<12$ & $<8$ \\
\hline It-48 & 57,82 & 25,70 & 1,01 & 2,13 & 0,32 & 0,12 & 2,50 & 2,22 & 0,049 & 7,95 & 99,82 & 124 & $<2$ & 25 & 16 & 10 & $<12$ & $<8$ \\
\hline It-49 & 54,06 & 28,21 & 1,01 & 1,81 & 0,34 & 0,12 & 2,52 & 2,43 & 0,095 & 9,14 & 99,74 & 116 & 4 & 23 & 21 & 9 & $<12$ & $<8$ \\
\hline It-50 & 51,82 & 26,93 & 1,03 & 7,17 & 0,34 & 0,10 & 2,60 & 2,32 & 0,064 & 7,43 & 99,80 & 133 & 3 & 23 & 40 & $<8$ & $<12$ & 11 \\
\hline It-51 & 51,00 & 28,46 & 1,06 & 5,93 & 0,36 & $<0,10$ & 2,73 & 2,61 & 0,118 & 7,43 & 99,70 & 125 & $<2$ & 25 & 16 & 10 & $<12$ & $<8$ \\
\hline It-52 & 35,76 & 16,46 & 0,76 & 33,83 & 0,35 & 0,11 & 1,58 & 1,42 & 0,199 & 9,48 & 99,95 & 119 & $<2$ & 20 & 13 & 16 & $<12$ & 9 \\
\hline It-53 & 55,94 & 27,93 & 1,10 & 0,77 & 0,32 & $<0,10$ & 2,46 & 2,53 & 0,038 & 8,58 & 99,67 & 124 & 3 & 26 & 27 & 8 & $<12$ & $<8$ \\
\hline It-54 & 53,70 & 25,71 & 1,30 & 4,84 & 0,56 & $\begin{array}{l}0,66 \\
\end{array}$ & 2,27 & 2,36 & 0,190 & 8,15 & 99,74 & 187 & $<2$ & 30 & $<2$ & 9 & $<12$ & 9 \\
\hline It-55 & 52,77 & 26,26 & 1,29 & 5,32 & 0,35 & 0,26 & 2,27 & 2,40 & 0,203 & 8,62 & 99,74 & 176 & 3 & 31 & $<2$ & $<8$ & $<12$ & $<8$ \\
\hline It-56 & 51,88 & 24,01 & 1,24 & 10,34 & 0,33 & 0,32 & 2,11 & 2,16 & 0,458 & 6,99 & 99,84 & 201 & $<2$ & 28 & 3 & $<8$ & $<12$ & 10 \\
\hline It-57 & 55,11 & 23,30 & 1,36 & 5,90 & 0,59 & 0,93 & 1,94 & 2,14 & 0,236 & 8,12 & 99,63 & 236 & $<2$ & 32 & $<2$ & 9 & $<12$ & $<8$ \\
\hline It-58 & 56,46 & 25,66 & 1,52 & 3,76 & 0,32 & $<0,10$ & 2,20 & 2,39 & 0,114 & 7,32 & 99,74 & 236 & 3 & 35 & $<2$ & 10 & $<12$ & 8 \\
\hline It-59 & 57,37 & 23,72 & 1,37 & 5,10 & 0,29 & 0,15 & 2,04 & 2,15 & 0,168 & 7,44 & 99,80 & 264 & $<2$ & 33 & 2 & 8 & $<12$ & 8 \\
\hline It -60 & 59,09 & 23,34 & 1,53 & 3,46 & 0,37 & 0,20 & 1,90 & 2,25 & 0,159 & 7,51 & 99,81 & 299 & $<2$ & 36 & 2 & 8 & $<12$ & 9 \\
\hline It-61 & 54,33 & 22,62 & 1,00 & 5,20 & 0,75 & 1,78 & 1,95 & 1,98 & 0,296 & 9,15 & 99,06 & 160 & $<2$ & 26 & 6 & $<8$ & $<12$ & $<8$ \\
\hline \begin{tabular}{l|l|} 
It-66 \\
\end{tabular} & 57,26 & 17,85 & 1,17 & 6,95 & 0,35 & 1,95 & 1,54 & 1,66 & 0,292 & 9,84 & 98,86 & 246 & $<2$ & 29 & 3 & $<8$ & $<12$ & $<8$ \\
\hline It-63 & 55,77 & 23,55 & 1,27 & 6,16 & 0,41 & 0,55 & 1,63 & 2,22 & 0,186 & 7,94 & 99,69 & 180 & $<2$ & 29 & $<2$ & $<8$ & $<12$ & $<8$ \\
\hline
\end{tabular}


Continuación Anexo 1.

\begin{tabular}{|c|c|c|c|c|c|c|c|c|c|c|c|c|c|c|c|c|c|c|}
\hline \multirow{2}{*}{ Código } & \multicolumn{9}{|c|}{ Resultados Elementos Mayores (\% en peso) por FRX } & \multirow{2}{*}{ Grav } & \multirow[b]{2}{*}{ Total } & \multicolumn{7}{|c|}{ ppm (FRX) } \\
\hline & $\mathrm{SiO}_{2}$ & $\mathrm{Al}_{2} \mathrm{O}_{3}$ & $\mathrm{TiO}_{2}$ & $\mathrm{Fe}_{2} \mathrm{O}_{3} \mathrm{~T}$ & $\mathrm{MgO}$ & $\mathrm{CaO}$ & $\mathrm{Na}_{2} \mathrm{O}$ & $\mathrm{K}_{2} \mathrm{O}$ & $\mathrm{P}_{2} \mathrm{O}_{5}$ & & & $\mathrm{Zr}$ & Ge & $\mathbf{N b}$ & Mo & Sn & Sb & Hf \\
\hline It-64 & 57,68 & 23,61 & 1,20 & 4,42 & 0,55 & 0,67 & 1,70 & 2,20 & 0,153 & 7,52 & 99,70 & 161 & 2 & 28 & $<2$ & 8 & $<12$ & 8 \\
\hline $\begin{array}{ll}\mathrm{It}-65 \\
\end{array}$ & 61,56 & 16,52 & 0,91 & 7,21 & 0,82 & 0,93 & 1,39 & 1,51 & 0,195 & 8,48 & 99,53 & 233 & $<2$ & 24 & 5 & $<8$ & $<12$ & 10 \\
\hline It-66 & $\overline{53,07}$ & 25,20 & 1,21 & 6,23 & 0,40 & 0,23 & 1,98 & 2,34 & 0,107 & 9,04 & 99,81 & 159 & $<2$ & 30 & 3 & $<8$ & $<12$ & $<8$ \\
\hline It-67 & 55,82 & 24,59 & 1,32 & 5,08 & 0,36 & 0,28 & 1,65 & 2,36 & 0,233 & 8,10 & 99,79 & 199 & $<2$ & 32 & $<2$ & 8 & $<12$ & $<8$ \\
\hline It-68 & 54,39 & 24,72 & 1,39 & 5,22 & 0,41 & 0,21 & 1,52 & 2,37 & 0,143 & 9,46 & 99,83 & 185 & $<2$ & 32 & $<2$ & 9 & $<12$ & $<8$ \\
\hline Pava-1 & 70,52 & 13,58 & 0,54 & 0,87 & 0,21 & 0,26 & 0,22 & 2,89 & 0,280 & 10,18 & 99,55 & 98 & 2 & 12 & 815 & $<8$ & 16 & $<8$ \\
\hline $\begin{array}{l}\text { Pava-2 } \\
\end{array}$ & 68,78 & 12,94 & 0,48 & 1,89 & 0,20 & $\begin{array}{c}<0,10 \\
\end{array}$ & 0,12 & 2,97 & 0,120 & 12,02 & 99,52 & 100 & 3 & 13 & 279 & $<8$ & 19 & $<8$ \\
\hline Pava-3 & 58,61 & 18,65 & 0,93 & 3,01 & 0,19 & 0,15 & 6,76 & 1,68 & 0,031 & 9,80 & 99,81 & 134 & $<2$ & 20 & 146 & $<8$ & 16 & $<8$ \\
\hline Pava-4 & 59,24 & 18,14 & 0,87 & 2,85 & 0,21 & 0,14 & 3,84 & 2,21 & 0,114 & 12,00 & 99,61 & 132 & $<2$ & 16 & 189 & $<8$ & 14 & $<8$ \\
\hline Pava-5 & 55,18 & 21,93 & 0,99 & 3,83 & 0,25 & 0,28 & 5,33 & 2,81 & 0,111 & 9,05 & 99,76 & 157 & 3 & 25 & 110 & $<8$ & 16 & 9 \\
\hline Pava-6 & 49,28 & 20,09 & 0,87 & 4,84 & 0,28 & 0,61 & 5,24 & 2,13 & 0,354 & 15,86 & 99,55 & 117 & 3 & 18 & 147 & $<8$ & 29 & $<8$ \\
\hline $\begin{array}{l}\text { Pava-7 } \\
\end{array}$ & 52,53 & 14,21 & 0,10 & 13,65 & 0,13 & 0,18 & $\begin{array}{ll}7,87 \\
\end{array}$ & $<0,08$ & \begin{tabular}{c|}
$<0,024$ \\
\end{tabular} & 11,25 & 99,92 & 43 & $<2$ & 16 & 3 & $<8$ & 14 & $<8$ \\
\hline Pava-8 & 67,69 & 18,23 & 0,45 & 0,15 & $<0,10$ & 0,12 & 10,57 & $<0,08$ & $<0,024$ & 2,58 & 99,79 & 79 & 2 & 11 & 5 & $<8$ & 15 & $<8$ \\
\hline Pava-9 & 62,58 & 19,73 & 0,51 & 0,57 & 0,15 & 0,22 & 8,74 & 0,88 & 0,124 & 6,24 & 99,74 & 104 & 2 & 13 & 49 & $<8$ & $<12$ & $<8$ \\
\hline Pava-10 & 58,11 & 15,27 & 0,77 & 4,30 & 0,67 & 3,88 & 0,90 & 2,95 & 0,431 & 11,49 & 98,77 & 133 & 2 & 17 & 65 & $<8$ & 15 & $<8$ \\
\hline Pava-11 & 57,16 & 23,58 & 1,05 & 1,53 & 0,38 & 0,15 & 0,68 & 4,94 & 0,140 & 10,09 & 99,70 & 178 & 2 & 24 & 95 & 8 & 20 & $<8$ \\
\hline Pava-12 & 45,64 & 9,95 & 0,31 & 4,35 & 1,21 & 14,63 & 5,10 & $<0,08$ & 0,336 & 15,97 & 97,50 & 63 & $<2$ & 10 & 110 & $<8$ & 16 & $<8$ \\
\hline $\begin{array}{l}\text { Pava-13 } \\
\end{array}$ & 54,70 & 19,07 & 0,74 & 3,39 & 0,34 & 0,81 & 0,24 & 3,99 & 0,576 & 15,66 & 99,52 & 108 & $<2$ & 16 & 237 & $<8$ & 19 & $<8$ \\
\hline Pava-14 & 9,74 & 2,88 & 0,05 & 4,55 & 14,43 & 27,16 & 1,23 & 0,13 & 0,123 & 38,36 & 98,65 & 25 & $<2$ & 5 & 30 & 10 & $<12$ & $<8$ \\
\hline Pava-15 & 61,09 & 13,83 & 0,64 & 4,99 & 0,29 & 2,47 & 0,23 & 2,72 & 0,465 & 12,74 & 99,47 & 115 & $<2$ & 15 & 79 & $<8$ & 18 & $<8$ \\
\hline Pava-16 & 53,94 & 10,22 & 0,41 & 3,91 & 0,59 & 11,55 & 0,30 & 1,54 & 0,420 & 13,92 & 96,80 & 94 & $<2$ & 11 & 50 & $<8$ & 18 & 11 \\
\hline $\begin{array}{l}\text { Pava-17 } \\
\end{array}$ & 53,57 & 24,19 & 0,90 & 3,94 & 0,33 & 0,41 & 2,15 & 2,44 & 0,306 & 11,44 & 99,68 & 136 & 5 & 23 & 95 & $<8$ & 31 & $\begin{array}{l}<8 \\
\end{array}$ \\
\hline $\begin{array}{l}\text { Pava-18 } \\
\end{array}$ & 62,41 & 15,53 & 0,71 & 4,17 & 0,25 & 0,58 & 1,20 & 1,58 & 0,405 & 12,89 & 99,73 & 105 & 2 & 16 & 125 & $<8$ & 23 & 8 \\
\hline Pava-19 & 64,44 & 16,40 & 0,42 & 1,87 & 0,25 & 0,54 & 0,73 & 1,88 & 0,229 & 12,78 & 99,54 & 85 & $<2$ & 11 & 600 & $<8$ & 22 & 9 \\
\hline $\begin{array}{ll}\text { Tu-1 } \\
\end{array}$ & 44,67 & 13,29 & 0,68 & 2,03 & 1,44 & 15,45 & 1,64 & 2,63 & 0,324 & 16,50 & 98,65 & 111 & $<2$ & 13 & 3 & $<8$ & $<12$ & $<8$ \\
\hline Tu-2 & 27,16 & 7,91 & 0,24 & 4,20 & 7,76 & 20,49 & 1,64 & 1,24 & 0,283 & 26,23 & 97,15 & 47 & $<2$ & 10 & 5 & $<8$ & $<12$ & $<8$ \\
\hline Tu-3 & 35,46 & 7,02 & 0,52 & 3,53 & 6,01 & 19,06 & 1,12 & 1,16 & 0,392 & 23,53 & 97,80 & 101 & $<2$ & 12 & 2 & $<8$ & $<12$ & 13 \\
\hline Tu-4 & 21,86 & 5,29 & 0,10 & 4,03 & 6,44 & 28,25 & 2,20 & 0,36 & 0,152 & 28,83 & 97,51 & 32 & $<2$ & 6 & 4 & $<8$ & $<12$ & 125 \\
\hline Tu-5 & 45,96 & 13,73 & 0,66 & 5,56 & 0,81 & 4,26 & 2,49 & 2,37 & 0,619 & 21,91 & 98,37 & 108 & $<2$ & 16 & 4 & $<8$ & 12 & 13 \\
\hline Tu-6 & 33,96 & 8,73 & 0,12 & 3,22 & 7,13 & 17,87 & 4,20 & 0,35 & 0,139 & 21,80 & 97,52 & 37 & $<2$ & 6 & 2 & $<8$ & $<12$ & 8 \\
\hline Tu-7 & 52,00 & 18,26 & 0,81 & 2,98 & 0,38 & 3,96 & 0,38 & 4,01 & 0,344 & 14,66 & 97,78 & 105 & $<2$ & 19 & 179 & $<8$ & 22 & $<8$ \\
\hline Tu-8 & 37,02 & 9,33 & 0,34 & 1,20 & 0,94 & 23,45 & 3,60 & 0,69 & 0,304 & 20,68 & 97,55 & 78 & $<2$ & 9 & 4 & $<8$ & $<12$ & 24 \\
\hline Tu-9 & 48,62 & 13,86 & 0,33 & 8,64 & 1,51 & 4,70 & 7,09 & 0,31 & 0,411 & 12,81 & 98,28 & 65 & $<2$ & 15 & 142 & $<8$ & 16 & 9 \\
\hline Tu-10 & 59,61 & 14,31 & 0,96 & 4,77 & 0,35 & 2,85 & 7,18 & 0,40 & 0,497 & 7,81 & 98,74 & 168 & $<2$ & 17 & 73 & $<8$ & 19 & 26 \\
\hline Tu-11 & 35,61 & 9,92 & 0,29 & 6,27 & 5,68 & 15,19 & 5,11 & 0,28 & 0,065 & $\begin{array}{ll}18,32 \\
\end{array}$ & 96,74 & 61 & $<2$ & 8 & 3 & $<8$ & $<12$ & $<8$ \\
\hline Tu-12 & 27,08 & 7,02 & 0,15 & 4,27 & 9,23 & 19,96 & 3,40 & 0,38 & 0,105 & 26,68 & 98,28 & 39 & $<2$ & 5 & 2 & $<8$ & $<12$ & 20 \\
\hline Tu-13 & 47,16 & 13,42 & 0,62 & 4,91 & 1,30 & 9,37 & 5,14 & 1,16 & 0,304 & 12,78 & 96,16 & 107 & $<2$ & 19 & 4 & $<8$ & $<12$ & 12 \\
\hline Tu-14 & 52,30 & 15,97 & 0,78 & 2,10 & 3,00 & 5,95 & 7,42 & 0,85 & 0,194 & 10,10 & $\begin{array}{l}98,66 \\
\end{array}$ & 132 & $<2$ & 13 & 4 & $<8$ & $<12$ & 13 \\
\hline
\end{tabular}

LOI: pérdida por ignición. $\mathrm{Fe}_{2} \mathrm{O}_{3} \mathrm{~T}$ : hierro total

\section{Anexo 2}

Resultados de los análisis composicionales de roca total mediante espectroscopía de masas con plasma acoplado inductivamente (ICP-MS).

\begin{tabular}{|c|c|c|c|c|c|c|c|c|c|c|c|c|c|c|c|c|c|c|c|c|c|c|c|c|}
\hline \multirow{2}{*}{ Código } & \multicolumn{24}{|c|}{ Resultados elementos traza (ppm) mediante ICP-MS } \\
\hline & $\mathbf{L i}$ & Cs & Be & $\mathbf{v}$ & $\mathbf{C r}$ & Sc & Mn & Co & $\mathrm{Ni}$ & $\mathrm{Cu}$ & $\mathbf{Z n}$ & Ga & As & Rb & $\mathrm{Sr}$ & Cd & In & Ва & $\mathbf{Y}$ & Tl & $\mathbf{P b}$ & Bi & Th & $\mathbf{U}$ \\
\hline It-1 & 38,6 & 8,0 & 4,3 & 288 & 130 & 18,8 & 13,6 & 1,7 & 15,7 & 14,0 & 25,5 & 32,1 & 11,8 & 182,2 & 124 & 0,3 & 0,0 & 607 & 2,7 & 1,8 & 4,0 & 0,4 & 16,9 & 2,1 \\
\hline It-2 & 35,2 & 8,1 & 4,1 & 266 & 120 & 19,5 & 12,5 & 0,8 & 10,0 & 10,1 & 14,4 & 30,4 & 4,3 & 174,3 & 120 & 0,3 & 0,0 & 609 & 2,9 & 1,7 & 3,1 & 0,3 & 18,2 & 2,1 \\
\hline It-3 & 19,7 & 3,1 & 7,3 & 220 & 82 & 24,0 & 845,4 & 64,1 & 389,6 & 27,0 & 487,9 & 23,3 & 14,5 & 124,7 & 80 & 9,0 & 0,0 & 459 & 9,7 & 1,6 & 6,3 & 0,2 & 11,4 & 2,1 \\
\hline It-4 & 43,2 & 9,3 & 5,0 & 261 & 130 & 19,1 & 11,1 & 1,7 & 14,0 & 11,8 & 42,3 & 33,4 & 6,9 & 187,4 & 140 & 0,3 & 0,0 & 621 & 2,4 & 1,6 & 5,0 & 0,6 & 18,5 & 2,0 \\
\hline It-5 & 43,2 & 7,0 & 4,1 & 458 & 130 & 25,7 & 44,5 & 1,8 & 26,5 & 63,5 & 65,5 & 33,8 & 10,6 & 191,0 & 109 & 0,5 & 0,1 & 714 & 3,8 & 2,0 & 6,0 & 0,3 & 9,9 & 2,0 \\
\hline It -6 & 37,8 & 7,0 & 4,4 & 190 & 112 & 16,8 & 238,1 & 2,1 & 23,2 & 20,3 & 57,4 & 30,2 & 11,6 & 159,0 & 122 & 0,5 & 0,0 & 534 & 4,1 & 1,6 & 5,8 & 0,5 & 12,6 & 2,2 \\
\hline It-7 & 31,1 & 7,0 & 4,0 & 358 & 109 & 14,8 & 111,8 & 16,4 & 118,6 & 48,1 & 63,1 & 25,6 & 12,9 & 138,5 & 91 & 1,0 & 0,0 & 446 & 4,4 & 2,9 & 13,9 & 0,6 & 18,5 & 2,3 \\
\hline It-8 & 40,5 & 10,3 & 4,5 & 244 & 113 & 15,0 & 43,7 & 13,9 & 88,3 & 66,8 & 18,6 & 29,3 & 7,7 & 156,9 & 117 & 0,4 & 0,0 & 481 & 2,2 & 3,9 & 16,3 & 0,5 & 21,2 & 5,2 \\
\hline It-9 & 48,8 & 8,3 & 4,3 & 227 & 108 & 16,7 & 20,3 & 0,8 & 7,6 & 16,2 & 15,0 & 31,0 & 4,8 & 149,4 & 133 & 0,5 & 0,0 & 495 & 2,6 & 1,6 & 3,7 & 0,6 & 11,2 & 1,6 \\
\hline It-10 & 14,5 & 4,0 & 1,8 & 738 & 158 & 12,2 & 6,3 & 0,4 & 17,7 & 7,1 & 6,7 & 19,6 & 2,9 & 112,9 & 48 & 0,4 & 0,0 & 435 & 1,8 & 1,2 & 3,3 & 0,3 & 7,8 & 11,3 \\
\hline It-11 & 34,2 & 7,3 & 3,2 & 732 & 152 & 13,3 & 7,0 & 0,3 & 7,8 & 13,9 & 11,1 & 28,1 & 13,6 & 129,0 & 86 & 0,3 & 0,1 & 391 & 7,5 & 1,4 & 12,5 & 0,5 & 17,1 & 5,5 \\
\hline It-12 & 36,5 & 6,7 & 3,4 & 1884 & 154 & 21,0 & 6,7 & 0,3 & 12,2 & 8,7 & 17,7 & 35,2 & 17,0 & 177,6 & 80 & 0,4 & 0,0 & 545 & 3,3 & 2,4 & 8,2 & 0,3 & 7,9 & 4,3 \\
\hline It-13 & 48,3 & 7,0 & 3,3 & 678 & 138 & 14,9 & 8,8 & 0,3 & 7,6 & 33,7 & 10,8 & 27,5 & 2,2 & 103,4 & 98 & 0,3 & 0,0 & 310 & 5,4 & 1,1 & 2,4 & 0,5 & 13,6 & 4,3 \\
\hline It-14 & 50,5 & 5,7 & 3,3 & 1018 & 184 & 14,1 & 5,3 & 0,3 & 15,9 & 26,5 & 12,4 & 28,1 & 10,4 & 106,1 & 112 & 0,4 & 0,1 & 356 & 4,8 & 1,6 & 9,0 & 0,6 & 9,2 & 3,9 \\
\hline It-15 & 44,5 & 4,6 & 2,8 & 922 & 126 & 13,7 & 6,0 & 0,7 & 28,6 & 12,9 & 92,9 & 22,1 & 24,1 & 84,8 & 91 & 0,4 & 0,0 & 286 & 3,8 & 1,5 & 4,9 & 0,3 & 3,6 & 2,1 \\
\hline It-16 & 49,7 & 5,9 & 2,7 & 1019 & 216 & 12,8 & 14,0 & 0,7 & 24,2 & 18,8 & 16,1 & 28,2 & 10,6 & 114,7 & 108 & 0,5 & 0,1 & 380 & 2,8 & 1,6 & 2,5 & 0,5 & 8,5 & 3,3 \\
\hline It-17 & 31,8 & 4,9 & 2,1 & 1231 & 214 & 14,6 & 13,4 & 1,3 & 55,2 & 28,7 & 43,4 & 24,7 & 166,4 & 109,1 & 63 & 1,2 & 0,1 & 391 & 6,5 & 1,4 & 24,8 & 0,4 & 10,4 & 5,3 \\
\hline
\end{tabular}


Continuación Anexo 2.

\begin{tabular}{|c|c|c|c|c|c|c|c|c|c|c|c|c|c|c|c|c|c|c|c|c|c|c|c|c|}
\hline \multirow{2}{*}{ Código } & \multicolumn{24}{|c|}{ Resultados elementos traza (ppm) mediante ICP-MS } \\
\hline & $\mathbf{L i}$ & Cs & Be & V & Cr & Sc & Mn & Co & $\mathrm{Ni}$ & $\mathbf{C u}$ & $\mathbf{Z n}$ & Ga & As & $\mathbf{R b}$ & $\mathrm{Sr}$ & Cd & In & Ва & $\mathbf{Y}$ & TI & $\mathbf{P b}$ & $\mathbf{B i}$ & Th & $\mathbf{U}$ \\
\hline It-18 & 38,4 & 5,9 & 2,1 & 1310 & 240 & 13,4 & 4,3 & 0,3 & 23,1 & 12,6 & 10,3 & 26,4 & 6,8 & 115,8 & 77 & 0,3 & 0,0 & 362 & 4,1 & 1,3 & 2,2 & 0,4 & 7,3 & 3,3 \\
\hline It-19 & 50,6 & 7,0 & 2,7 & 1016 & 207 & 12,9 & 11,9 & 1,0 & 14,9 & 23,6 & 13,9 & 29,2 & 5,5 & 116,9 & 81 & 0,3 & 0,0 & 360 & 3,6 & 1,1 & 2,7 & 0,6 & 6,2 & 3,5 \\
\hline It -20 & 39,3 & 3,9 & 2,0 & 848 & 159 & 10,6 & 7,3 & $\overline{0,3}$ & 16,8 & 11,0 & 9,8 & 22,4 & 8,8 & 83,8 & 62 & 0,4 & 0,0 & 273 & 2,6 & 0,8 & 2,3 & 0,4 & 10,5 & $\overline{1,6}$ \\
\hline It-21 & 42,9 & 4,9 & 2,2 & 895 & 185 & 12,3 & 10,0 & 0,4 & 19,3 & 13,7 & 13,2 & 27,5 & 21,3 & 103,5 & 58 & 0,5 & 0,0 & 318 & 2,9 & 1,1 & 4,7 & 0,6 & 8,7 & 1,7 \\
\hline It-22 & 53,0 & 2,8 & 2,3 & 609 & 115 & 11,0 & 5,7 & 0,4 & 10,1 & 24,4 & 10,1 & 22,1 & 10,9 & 87,0 & 47 & 0,6 & 0,0 & 255 & 4,4 & 0,8 & 4,4 & 0,3 & 2,7 & 2,1 \\
\hline It-23 & 22,6 & 4,7 & 2,6 & 2051 & 290 & 20,3 & 8,0 & 0,5 & 11,2 & 9,9 & 25,7 & 33,0 & 22,9 & 169,3 & 26 & 0,2 & 0,0 & 417 & 3,5 & 1,9 & 4,0 & 0,6 & 8,4 & 2,3 \\
\hline It-24 & 0,9 & 0,4 & 0,6 & 1445 & 196 & 10,8 & 5,9 & 0,3 & 8,1 & 7,5 & 10,8 & 18,0 & 2,6 & 22,3 & 41 & $\overline{0,6}$ & 0,0 & 39 & 6,9 & 0,3 & 5,9 & 0,6 & 1,4 & 0,9 \\
\hline It-25 & 2,0 & 0,4 & 0,6 & 426 & 99 & 41,7 & 914,8 & 8,2 & 49,0 & 7,2 & 91,2 & 11,3 & 8,5 & 21,6 & 50 & 1,2 & 0,0 & 37 & 13,4 & 0,2 & 4,2 & 0,2 & 16,7 & 1,7 \\
\hline It -26 & 4,5 & 1,3 & 1,6 & 86 & 35 & 9,6 & 613,6 & 8,5 & 29,1 & 24,8 & 100,0 & 14,7 & 2,1 & 60,6 & 110 & 1,2 & 0,0 & 244 & 10,1 & 0,4 & 8,2 & $\overline{0,2}$ & 5,8 & $\overline{1,4}$ \\
\hline It-27 & 3,8 & 0,9 & 2,5 & 44 & 17 & 6,1 & 1712,8 & 8,6 & 35,9 & 42,1 & 54,4 & 7,1 & 4,0 & 51,4 & 130 & 0,6 & 0,0 & 485 & 14,2 & 0,4 & 4,1 & 0,5 & 3,9 & $\overline{1,6}$ \\
\hline It-28 & 17,7 & 0,9 & 1,2 & 117 & 49 & 9,9 & 8,6 & 9,4 & 24,3 & 14,2 & 627,0 & 17,8 & 8,2 & 25,6 & 23 & 2,5 & 0,1 & 44 & 3,7 & 0,3 & 5,6 & 0,1 & 7,7 & 1,1 \\
\hline It-29 & 73,4 & 7,6 & 3,2 & 261 & 90 & 15,4 & 11,1 & 2,1 & 20,2 & 7,0 & 19,7 & 31,5 & 8,3 & 82,0 & 53 & 0,2 & 0,0 & 188 & 3,7 & 1,8 & 6,1 & 0,5 & 22,4 & 1,5 \\
\hline It -30 & 78,6 & 8,1 & 3,4 & 486 & 108 & 14,8 & 14,5 & 5,2 & 23,0 & 7,6 & 13,7 & 33,3 & 7,1 & 91,9 & 56 & 0,2 & 0,0 & 224 & 2,7 & 2,2 & 5,9 & 0,5 & 8,8 & 1,2 \\
\hline It-31 & 75,8 & 6,7 & 2,4 & 1361 & 163 & 11,5 & 7,7 & 0,3 & 10,0 & 6,3 & 8,7 & 26,1 & $\overline{9,6}$ & 81,1 & 46 & 0,4 & 0,0 & 181 & 6,3 & 4,3 & 4,0 & 0,4 & 14,1 & 2,4 \\
\hline It-32 & 63,7 & 6,4 & 2,7 & 857 & 135 & 11,5 & 7,6 & 0,3 & 6,9 & 7,7 & 9,9 & 26,8 & 5,7 & 76,1 & 62 & 0,2 & 0,0 & 202 & 2,1 & 1,9 & 3,2 & 0,3 & 14,7 & 3,0 \\
\hline It-33 & 75,4 & 10,8 & 4,7 & 286 & 102 & 17,9 & 10,3 & 0,4 & 4,1 & 9,2 & 10,6 & 35,1 & 5,5 & 115,9 & 78 & 0,1 & 0,0 & 272 & 3,1 & 1,1 & 6,0 & 0,6 & 12,4 & 1,5 \\
\hline It-34 & 65,3 & 11,1 & 4,5 & 227 & 91 & 17,2 & 60,8 & 9,1 & 43,6 & 19,0 & 14,4 & 33,1 & 7,2 & \begin{tabular}{l|l}
118,0 \\
\end{tabular} & 79 & 0,1 & 0,0 & 291 & 2,3 & 1,1 & 9,2 & 0,5 & 16,2 & 1,4 \\
\hline It -35 & 63,5 & 8,8 & 3,0 & 246 & 99 & 15,9 & 9,3 & 0,3 & 3,5 & 6,1 & 10,1 & 28,8 & 5,5 & 99,1 & 117 & 0,1 & 0,0 & 274 & 3,1 & 1,5 & 16,7 & 0,5 & 13,5 & 1,5 \\
\hline It-36 & 68,6 & 10,1 & 3,3 & 352 & 113 & 16,2 & $\overline{7,7}$ & 0,2 & 3,1 & 8,2 & 9,4 & 30,6 & 8,7 & 106,2 & 127 & $\overline{0,1}$ & 0,0 & 285 & 3,2 & 1,3 & 6,6 & 0,5 & 10,7 & 2,2 \\
\hline It -37 & 64,8 & 13,4 & 3,8 & 312 & 104 & 16,9 & 14,3 & 0,6 & 4,2 & 9,0 & 12,9 & 34,2 & 6,3 & 137,6 & 140 & 0,2 & 0,0 & 367 & 2,8 & 1,5 & 5,6 & $\overline{0,5}$ & 15,4 & 1,2 \\
\hline It-38 & 58,4 & 10,2 & 4,2 & 109 & 89 & 16,1 & 35,5 & 30,0 & 49,7 & 15,7 & 12,6 & 29,3 & 6,6 & 128,9 & 128 & 0,1 & 0,0 & 395 & 1,2 & 1,0 & 9,4 & 1,4 & 12,7 & 1,5 \\
\hline It-39 & 60,7 & 9,4 & 4,0 & 100 & 84 & 15,3 & 57,6 & 4,7 & 18,5 & 11,7 & 19,1 & 29,8 & 8,2 & 128,9 & 135 & 0,2 & 0,1 & 394 & 1,7 & 0,9 & 6,8 & 0,4 & 14,2 & 1,5 \\
\hline It -40 & 57,0 & 8,4 & 4,1 & 90 & 74 & 16,7 & 140,7 & 13,7 & 28,4 & 9,3 & 15,2 & 26,6 & 5,4 & 113,8 & 120 & 0,2 & 0,1 & 353 & 2,1 & 0,8 & 4,9 & 0,4 & 13,7 & 1,6 \\
\hline It-41 & 48,0 & 9,1 & 3,2 & 103 & 78 & 15,5 & 17,4 & 1,8 & 9,1 & 6,4 & 11,1 & 26,3 & 6,6 & 111,2 & 95 & 0,1 & 0,0 & 328 & 1,5 & 0,7 & 4,0 & 0,4 & 14,5 & 0,9 \\
\hline It -42 & 55,5 & 7,4 & 3,8 & 79 & 67 & 16,2 & 280,1 & 7,4 & 24,1 & 8,0 & 15,4 & 24,7 & 7,3 & 106,4 & 109 & $\overline{0,2}$ & 0,1 & 315 & 2,0 & 0,7 & 3,9 & 0,4 & 15,0 & 1,6 \\
\hline It-43 & 51,3 & 9,4 & 3,6 & 96 & 80 & 17,0 & 41,9 & 2,0 & 13,9 & 7,3 & 14,1 & 28,0 & 7,9 & 123,3 & 121 & 0,1 & 0,1 & 372 & 1,3 & 0,8 & 4,2 & 0,5 & 14,6 & 1,3 \\
\hline It-44 & 62,7 & 6,4 & 3,6 & 82 & 71 & 17,6 & 104,3 & 1,0 & 12,8 & 6,3 & 12,8 & 24,8 & 7,2 & 93,9 & 119 & 0,1 & 0,1 & 276 & 1,5 & 0,7 & 3,1 & 0,4 & 11,0 & 1,1 \\
\hline It-45 & 57,0 & 7,6 & 3,2 & 88 & 74 & 15,6 & 51,9 & 2,7 & 12,0 & 7,3 & 19,6 & 24,5 & 6,9 & 103,6 & 116 & 0,1 & 0,1 & 307 & 1,5 & 0,7 & 5,0 & 0,4 & 12,3 & 1,4 \\
\hline It-46 & 56,9 & 9,4 & 3,3 & 103 & 80 & 15,6 & 17,2 & 1,1 & 7,5 & 7,5 & 11,5 & 27,1 & 3,6 & 119,2 & 128 & 0,1 & 0,0 & 363 & 1,9 & 0,9 & 10,0 & 0,5 & 13,1 & 1,2 \\
\hline It-47 & 56,2 & 8,3 & 3,2 & 135 & 84 & 14,6 & 249,1 & 6,7 & 30,3 & 12,0 & 16,2 & 24,5 & 10,1 & 110,1 & 123 & 0,2 & 0,0 & 303 & 2,0 & 1,3 & 14,8 & 0,6 & 8,1 & 1,1 \\
\hline It -48 & 61,1 & 10,0 & 3,4 & 192 & 137 & 15,4 & 64,1 & 3,6 & 30,7 & 9,5 & 16,5 & 29,7 & 7,9 & 127,0 & 161 & 0,3 & 0,0 & 384 & 3,3 & 1,4 & 12,5 & 0,5 & 10,9 & 1,6 \\
\hline It -49 & 54,8 & 13,0 & 3,0 & 420 & 123 & 16,8 & 89,0 & 4,5 & 34,7 & 39,6 & 17,9 & 29,6 & 5,2 & 133,1 & 152 & 0,4 & 0,1 & 416 & 3,4 & 2,1 & 7,8 & 0,5 & 11,3 & 2,8 \\
\hline It -50 & 59,0 & 11,0 & 4,1 & 309 & 135 & 17,4 & 171,7 & 8,0 & 61,6 & 30,5 & 36,0 & 29,0 & 14,6 & 123,1 & 150 & 0,5 & 0,1 & 348 & 4,1 & 1,3 & 3,4 & 0,4 & 13,8 & 2,6 \\
\hline It-51 & 62,8 & 9,2 & 4,0 & 200 & 101 & 20,6 & 176,2 & 9,2 & 43,9 & 13,7 & 59,4 & 29,9 & 9,8 & 134,4 & 173 & 0,4 & 0,0 & 399 & 2,5 & 1,3 & 10,4 & 0,5 & 13,7 & 2,0 \\
\hline It -52 & 43,9 & 8,5 & 2,6 & 128 & 59 & 12,5 & 357,5 & 15,1 & 95,4 & 77,6 & 207,4 & 17,9 & 10,9 & 74,2 & 102 & 1,2 & 0,0 & 217 & 2,2 & 1,5 & 12,0 & 0,3 & 11,2 & 2,3 \\
\hline It-53 & 54,0 & 11,5 & 3,0 & 371 & 121 & 16,1 & 7,7 & 0,2 & 2,9 & 7,8 & 10,1 & 29,2 & 5,3 & 137,3 & 165 & 0,2 & 0,0 & 408 & 2,3 & 2,2 & 3,7 & 0,6 & 10,7 & 1,6 \\
\hline It-54 & 57,3 & 10,1 & 3,5 & 94 & 81 & 18,8 & 181,2 & 13,1 & 34,7 & 24,8 & 24,8 & 27,6 & 2,4 & 138,1 & 150 & 0,4 & 0,1 & 392 & 2,2 & 1,3 & 8,7 & 0,4 & 13,6 & 1,6 \\
\hline It -55 & 79,2 & 12,0 & 4,6 & 98 & 85 & 19,3 & 113,1 & 16,7 & 31,9 & 17,2 & 35,6 & 33,0 & 4,9 & 162,2 & 161 & 0,4 & 0,1 & 395 & 2,4 & 1,6 & 10,5 & 1,0 & 16,2 & 1,7 \\
\hline It-56 & 179,0 & 10,6 & 4,4 & 88 & 77 & 22,9 & 172,5 & 8,2 & 32,7 & 16,7 & 34,1 & 30,6 & 5,7 & 147,1 & 141 & 0,4 & 0,1 & 348 & 3,6 & 1,4 & 6,3 & 0,6 & 15,2 & 3,6 \\
\hline It-57 & 153,1 & 10,3 & 4,2 & 82 & 73 & 18,7 & 305,4 & 10,1 & 37,4 & 11,4 & 25,1 & 29,3 & 4,1 & 143,2 & 134 & 0,5 & 0,1 & 382 & 3,1 & 1,3 & 4,6 & 0,6 & 17,6 & 1,8 \\
\hline It -58 & 81,8 & 12,1 & 4,5 & 89 & 83 & 18,8 & 37,7 & 2,0 & 12,3 & 8,1 & 22,2 & 33,7 & 6,1 & 167,2 & 161 & 0,4 & 0,1 & 415 & 2,2 & 1,6 & 10,1 & 0,9 & 16,9 & 1,3 \\
\hline It-59 & 75,3 & 11,0 & 4,2 & 83 & 76 & 16,9 & 130,5 & 4,9 & 13,2 & 10,1 & 33,0 & 30,4 & 5,3 & 146,6 & 149 & 0,3 & 0,1 & 362 & 2,0 & 1,4 & 4,8 & 0,5 & 14,5 & 1,3 \\
\hline It -60 & 63,5 & 11,9 & 4,0 & 78 & 77 & 14,9 & 87,5 & 5,7 & 14,0 & 10,9 & 18,9 & 30,9 & 7,6 & 151,6 & 141 & 0,6 & 0,1 & 380 & 1,9 & 1,5 & 16,8 & 1,2 & 15,3 & 1,5 \\
\hline It-61 & 110,6 & 10,9 & 4,0 & 111 & 87 & 15,5 & 267,1 & 21,2 & 60,1 & 41,5 & 60,9 & 30,1 & 3,5 & 143,6 & 139 & 0,9 & 0,1 & 326 & 3,4 & 1,7 & 23,4 & 0,9 & 4,9 & 2,2 \\
\hline It -62 & 78,9 & 8,1 & 3,4 & 66 & 61 & 13,9 & 374,6 & 18,3 & 34,4 & 25,9 & 43,7 & 23,0 & 5,8 & 113,7 & 116 & 0,7 & 0,1 & 272 & 2,6 & 1,1 & 9,2 & 0,5 & 12,8 & 1,4 \\
\hline It -63 & 64,2 & 12,9 & 4,8 & 78 & 74 & 20,4 & 278,2 & 9,8 & 25,3 & 13,1 & 31,2 & 31,6 & 4,1 & 157,9 & 128 & 0,8 & 0,1 & 384 & 2,8 & 1,5 & 6,2 & 0,7 & 15,7 & 1,7 \\
\hline It -64 & 70,6 & 13,8 & 4,7 & 81 & 79 & 18,5 & 177,6 & 17,2 & 33,9 & 16,9 & 51,8 & 33,2 & 2,3 & 169,6 & 130 & 0,6 & 0,1 & 386 & 2,3 & 1,6 & 7,5 & 0,7 & 14,2 & 1,5 \\
\hline It -65 & 56,7 & 7,7 & 3,4 & 65 & 60 & 15,2 & 457,0 & 16,5 & 47,0 & 20,9 & 47,9 & 21,0 & 3,9 & 106,9 & 106 & 2,6 & 0,1 & 244 & 3,9 & 1,2 & 13,2 & 0,6 & 10,8 & 1,5 \\
\hline It-66 & 78,7 & 13,1 & 4,9 & 83 & 78 & 19,8 & 236,8 & 21,6 & 40,8 & 24,1 & 27,4 & 35,0 & 6,8 & 172,1 & 148 & 0,4 & 0,1 & 406 & 2,5 & 1,8 & 19,5 & 1,3 & 15,9 & 1,7 \\
\hline It-67 & 69,4 & 13,1 & 4,7 & 76 & 73 & 18,8 & 115,3 & 7,8 & 19,3 & 16,1 & 25,6 & 32,7 & 6,8 & 165,0 & 131 & 0,5 & 0,1 & 394 & 2,6 & 1,6 & 7,3 & 1,1 & 16,8 & 1,6 \\
\hline It-68 & 96,0 & 15,0 & 5,3 & 91 & 86,3 & 21,7 & 143,6 & 5,4 & 16,7 & 13,4 & 54,7 & 36,8 & 7,6 & 184,4 & 134 & 0,6 & 0,1 & 436 & 2,5 & 1,8 & 5,0 & 0,6 & 19,8 & 1,8 \\
\hline Pava-1 & 71,6 & 2,2 & 2,1 & 2122 & 166,9 & 16,2 & 4,8 & 0,8 & 53,1 & 11,8 & 24,5 & 25,5 & 79,6 & 149,4 & 16 & 1,5 & 0,0 & 324 & 2,6 & 2,2 & 8,0 & 0,5 & 4,6 & 8,6 \\
\hline Pava-2 & 5,3 & 2,4 & 2,4 & 1820 & 190,1 & 12,6 & 10,8 & 3,4 & 87,2 & 43,5 & 17,1 & 21,8 & 55,7 & 151,3 & 20 & 0,8 & 0,0 & 339 & 7,1 & 3,1 & 10,3 & 0,3 & 10,7 & 15,4 \\
\hline Pava-3 & 4,1 & 2,2 & 1,8 & 559 & 146,9 & 15,2 & 22,9 & 7,2 & 98,3 & 42,2 & 27,9 & 23,4 & 28,6 & 90,6 & 44 & 0,5 & 0,0 & 190 & 3,4 & 3,2 & 9,0 & 0,8 & 16,8 & 4,7 \\
\hline Pava-4 & 4,0 & 2,3 & 1,9 & 584 & 155,1 & 15,4 & 23,3 & 7,2 & 99,7 & 43,1 & 28,8 & 23,4 & 27,8 & 89,9 & 44 & 0,5 & 0,0 & 192 & 3,4 & 3,2 & 9,1 & 0,9 & 15,5 & $\overline{4,5}$ \\
\hline Pava-5 & 6,3 & 3,4 & 2,7 & 1432 & 180,7 & 14,1 & 17,1 & 3,5 & 228,2 & 89,7 & 55,7 & 25,7 & 52,5 & 125,3 & 29 & 0,8 & 0,1 & 296 & 20,4 & 2,6 & 10,3 & 0,8 & 11,3 & 8,1 \\
\hline Pava-6 & 8,5 & 4,6 & 4,2 & 381 & 119,6 & 24,2 & 44,4 & 12,2 & 82,1 & 42,4 & 32,6 & 35,4 & 42,4 & 146,5 & 54 & 0,5 & 0,0 & 282 & 3,7 & 2,5 & 11,2 & 0,7 & 22,2 & 4,5 \\
\hline Pava-7 & 15,1 & 5,0 & 2,6 & 1605 & 216,2 & 16,7 & 46,9 & 9,5 & 289,4 & 98,6 & 155,2 & 28,3 & 68,6 & 101,6 & 36 & 1,6 & 0,0 & 231 & 7,8 & 6,5 & 22,7 & 0,4 & 10,4 & 15,8 \\
\hline Pava-8 & 0,8 & 0,1 & 0,4 & 12 & 5,2 & 0,3 & 2,8 & 7,9 & 46,3 & 32,5 & 61,0 & 11,3 & 6,3 & 1,5 & 51 & 1,0 & 0,0 & 10 & 1,0 & 0,1 & 8,9 & 0,2 & 1,1 & 0,4 \\
\hline Pava-9 & 1,5 & 0,1 & 0,3 & 35 & 11,7 & 0,3 & 2,7 & 0,4 & 4,1 & 8,1 & 6,2 & 14,6 & 1,9 & 1,0 & 39 & 0,1 & 0,0 & 10 & 0,8 & 0,1 & 33,6 & 0,1 & 0,8 & 0,3 \\
\hline $\begin{array}{l}\text { Pava- } \\
10\end{array}$ & 1,2 & 0,6 & 0,9 & 304 & 85,5 & 7,7 & 1,9 & 1,1 & 16,2 & 8,5 & 40,8 & 22,1 & 12,6 & 33,2 & 53 & 0,2 & 0,0 & 78 & 8,4 & 0,4 & 65,9 & 0,2 & 34,1 & 2,0 \\
\hline
\end{tabular}




\section{Continuación Anexo 2.}

\begin{tabular}{|c|c|c|c|c|c|c|c|c|c|c|c|c|c|c|c|c|c|c|c|c|c|c|c|c|}
\hline \multirow{2}{*}{ Código } & \multicolumn{24}{|c|}{ Resultados elementos traza (ppm) mediante ICP-MS } \\
\hline & $\mathbf{L i}$ & Cs & Be & $\mathbf{V}$ & $\mathrm{Cr}$ & Sc & Mn & Co & $\mathrm{Ni}$ & $\mathrm{Cu}$ & Zn & Ga & As & $\mathbf{R b}$ & Sr & Cd & In & Ba & $\mathbf{Y}$ & Tl & $\mathbf{P b}$ & $\mathbf{B i}$ & Th & $\mathbf{U}$ \\
\hline Pava-11 & 15,2 & 3,7 & 2,9 & 651 & 141,1 & 13,0 & 123,2 & 10,7 & 145,3 & 26,9 & 52,1 & 29,0 & 51,4 & 129,6 & 25 & 1,4 & 0,1 & 315 & 14,4 & 2,8 & 8,8 & 0,2 & 33,0 & 3,9 \\
\hline $\begin{array}{c}\text { Pava- } \\
12\end{array}$ & 16,6 & 7,3 & 4,6 & 855 & 163,8 & 20,3 & 12,7 & 4,9 & 27,7 & 12,9 & 52,9 & 34,7 & 75,0 & 210,9 & 23 & 1,0 & 0,0 & 451 & 3,3 & 2,2 & 7,4 & 0,4 & 13,1 & 2,8 \\
\hline $\begin{array}{c}\text { Pava- } \\
13\end{array}$ & 65,9 & 0,3 & 2,0 & 56 & 22,7 & 8,2 & 355,4 & 4,9 & 137,6 & 34,3 & 192,5 & 4,2 & 99,9 & 2,0 & 63 & 9,6 & 0,0 & 19 & 14,7 & 2,0 & 5,3 & 0,1 & 3,4 & 6,9 \\
\hline $\begin{array}{c}\text { Pava- } \\
14\end{array}$ & 11,5 & 0,2 & 1,0 & 183 & 35,1 & 3,0 & 689,2 & 2,5 & 65,5 & 11,7 & 63,7 & 1,6 & 15,8 & 4,0 & 290 & 0,7 & 0,0 & 498 & 5,8 & 0,2 & 2,2 & $<0,05$ & 2,3 & 1,3 \\
\hline $\begin{array}{c}\text { Pava- } \\
15\end{array}$ & 7,3 & 3,4 & 2,8 & 1241 & 185,9 & 11,5 & 57,0 & 7,3 & 175,0 & 46,4 & 63,2 & 19,4 & 61,7 & 123,0 & 24 & 1,9 & 0,1 & 355 & 9,5 & 3,4 & 8,5 & 0,3 & 6,0 & 3,7 \\
\hline $\begin{array}{c}\text { Pava- } \\
16\end{array}$ & 15,2 & 2,7 & 1,2 & 717 & 145,1 & 11,6 & 261,7 & 8,0 & 141,1 & 28,7 & 95,7 & 14,2 & 34,7 & 86,3 & 56 & 3,4 & 0,1 & 392 & 15,3 & 2,6 & 6,4 & 0,2 & 6,1 & 4,4 \\
\hline $\begin{array}{c}\text { Pava- } \\
17\end{array}$ & 44,4 & 10,2 & 4,2 & 770 & 144,3 & 17,5 & 31,8 & 10,8 & 136,9 & 51,5 & 61,1 & 29,7 & 24,5 & 136,0 & 112 & 0,5 & 0,0 & 447 & 8,1 & 3,5 & 13,1 & 0,4 & 23,4 & 9,9 \\
\hline $\begin{array}{c}\text { Pava- } \\
18\end{array}$ & 28,3 & 5,5 & 2,7 & 833 & 138,9 & 11,9 & 25,5 & 8,6 & 184,8 & 41,7 & 55,6 & 19,2 & 29,3 & 97,2 & 76 & 1,1 & 0,0 & 412 & 8,0 & 3,8 & 22,9 & 0,2 & 9,4 & 4,3 \\
\hline Tu-1 & 7,6 & 2,2 & 1,7 & 71 & 32 & 7,8 & 1318 & 8,3 & 45,0 & 23,9 & 503 & 10,7 & 10,7 & 59,7 & 111 & 9,9 & 0,0 & 127 & 11,4 & 0,4 & 13,1 & 0,2 & 5,0 & 3,3 \\
\hline Tu-2 & 6,1 & 1,7 & 1,8 & 90 & 28 & 9,4 & 1565 & 11,9 & 42,2 & 27,5 & 127 & 11,6 & 7,3 & 58,9 & 98 & 1,5 & 0,0 & 108 & 11,7 & 0,3 & 6,8 & 0,1 & 4,3 & 1,5 \\
\hline Tu-3 & 13,9 & 4,0 & 3,3 & 132 & 52 & 15,4 & 550 & 11,8 & 41,5 & 35,0 & 62 & 22,8 & 18,1 & 130,9 & 82 & 1,2 & 0,1 & 167 & 11,9 & 0,4 & 9,3 & 0,3 & 6,5 & 1,7 \\
\hline Tu-4 & 6,1 & 1,0 & 2,0 & 156 & 57 & 13,6 & 509 & 6,3 & 23,0 & 12,6 & 497 & 23,7 & 11,3 & 34,0 & 61 & 15,2 & 0,0 & 85 & 11,2 & 0,1 & 7,5 & 0,2 & 8,7 & 1,6 \\
\hline Tu-5 & 7,9 & 1,1 & 1,5 & 132,0 & 52,5 & 12,5 & 545 & 17,9 & 42,6 & 20,8 & 294 & 19,0 & 20,7 & 43,7 & 48 & 6,8 & 0,0 & 88,2 & 10,2 & 0,2 & 9,5 & 0,2 & 5,3 & 2,6 \\
\hline Tu-6 & 2,3 & 0,3 & 0,9 & 35 & 13 & 6,5 & 1740 & 4,4 & 31,8 & 9,7 & 162 & 8,4 & 4,6 & 9,5 & 69 & 2,4 & 0,0 & 24 & 12,9 & 0,0 & 4,0 & 0,1 & 3,2 & 1,9 \\
\hline Tu-7 & 1,7 & 0,3 & 0,5 & 38 & 18 & 7,2 & 1284 & 10,8 & 34,3 & 22,1 & 74 & 8,0 & 2,9 & 6,9 & 69 & 1,0 & 0,0 & 40 & 5,5 & 0,0 & 2,9 & $<0,05$ & 4,1 & 0,8 \\
\hline Tu-8 & 3,4 & 0,8 & 0,7 & 537 & 125 & 9,4 & 189 & 9,6 & 162,9 & 27,9 & 2232 & 13,0 & 34,0 & 19,8 & 39 & 28 & 0,0 & 84 & 9,0 & 1,4 & 39,5 & 0,2 & 6,5 & 6,6 \\
\hline Tu-9 & 1,9 & 0,3 & 0,7 & 218 & 72 & 10,3 & 192 & 20,9 & 370,8 & 23,7 & 498 & 12,3 & 42,4 & 11,1 & 44 & 10,0 & 0,0 & 17 & 13,3 & 1,1 & 15,5 & 0,2 & 7,0 & 5,2 \\
\hline Tu-10 & 8,0 & 1,0 & 1,1 & 63 & 29 & 7,7 & 734 & 9,0 & 41,9 & 18,0 & 357 & 9,6 & 5,4 & 29,6 & 96 & 2,2 & 0,1 & 83 & 16,4 & 0,2 & 4,6 & 0,1 & 5,4 & 7,5 \\
\hline Tu-11 & 6,8 & 1,0 & 1,0 & 62 & 29 & 7,7 & 720 & 8,7 & 39,9 & 17,9 & 352 & 9,2 & 4,2 & 27,4 & 95 & 2,2 & 0,1 & 82 & 17,3 & 0,2 & 4,4 & 0,1 & 3,3 & 8,0 \\
\hline Tu-12 & 9,0 & 5,1 & 3,3 & 1897 & 251 & 17,8 & 100 & 5,5 & 155,4 & 28,3 & 222 & 33,1 & 105,5 & 189,8 & 26 & 2,4 & 0,1 & 388 & 9,9 & 4,7 & 9,9 & 0,4 & 19,8 & 11,1 \\
\hline Tu-13 & 3,1 & 0,4 & 1,0 & 38 & 16 & 5,9 & 1611 & 7,3 & 28,3 & 15,8 & 178 & 8,7 & 4,3 & 10,6 & 84 & 4,4 & 0,0 & 32 & 11,4 & 0,1 & 4,0 & 0,1 & 2,3 & 1,9 \\
\hline Tu-14 & 10,1 & 3,6 & 2,7 & 129 & 47 & 11,5 & 121 & 10,7 & 37,0 & 33,9 & 607 & 20,7 & 18,5 & 112,2 & 46 & 8,8 & 0,1 & 167 & 8,6 & 0,5 & 26,5 & 0,2 & 3,6 & 3,1 \\
\hline
\end{tabular}

